\title{
Revisiting the Role of Pornography Use in the Confluence Model Theory of Sexual
}

\section{Aggression}

\author{
Taylor Kohut ${ }^{1,3}$ Ph.D. and William A. Fisher ${ }^{1,2}$ Ph.D.
}

${ }^{1}$ Department of Psychology, the University of Western Ontario, London, Ontario, Canada

${ }^{2}$ Department of Obstetrics and Gynaecology, the University of Western Ontario, London, Ontario, Canada

${ }^{3}$ Institut de recherche en sciences psychologiques (IPSY), L'Université catholique de Louvain, Ottignies-Louvain-La-Neuve, Belgique

This research was funded by an Insight Grant (435 2017 0549) provided by the Social Sciences and Humanities Research Council of Canada (PI: William Fisher).

OSF Pre-registration Links: https://osf.io/eub2s/components (Study 1);

https://osf.io/sb98d/components (Study $2 \&$ 3)

Correspondence should be directed to Taylor Kohut at the University of Western Ontario, 7430

Social Science Centre, London, ON, N6A 3K7, Canada; e-mail: tkohut@uwo.ca

Acknowledgements: We would like to thank Stephanie Montgomery-Graham and Erin

Schumlich for their help with assembling study materials and recruiting participants.

Word count: 13,808; Figures: 4; Tables 7

Submitted: October 3, 2022 


\begin{abstract}
This research tested Confluence Model reasoning that pornography use should be related to sexual aggression among men who are high but not low in the predisposing risk factors of hostile masculinity (HM) and impersonal sexuality (IS). This hypothesis was examined with three online surveys of young adult males including an American Mechanical Turk sample $\left(N_{1}=\right.$ $1,528, M_{\text {age }}=22.46$ years $) ;$ a national sample of Canadian students $\left(N_{2}=1,049\right.$, Mage $=20.89$ years); and a national sample of Canadian non-students $\left(N_{3}=905, M_{a g e}=21.66\right.$ years $)$. As expected, synergistic interactions between HM and IS reliably predicted self-reported sexual aggression across samples. Results with respect to interactions with pornography use were more complex. The Confluence Model hypothesis was supported when pornography use was operationalized as the use of nine specific magazines but it was not supported when pornography use was operationalized with a contemporary inclusive approach that included use of internet materials. These discrepant findings are difficult to account for with Confluence Model theorizing and highlight the non-equivalence of pornography use measures in survey research.
\end{abstract} Keywords: pornography; sexual aggression; Confluence Model; individual differences; measurement. 


\section{Revisiting the Role of Pornography Use in the Confluence Model Theory of Sexual}

\section{Aggression}

Some have argued that the effects of pornography on sexual aggression may be limited to men who are otherwise predisposed to engage in sexual violence (Fisher et al., 2013; Fisher \& Barak, 2001; Malamuth, 2018; Seto et al., 2001). This view is well captured by the Confluence Model, which theorizes that two primary individual difference factors, hostile masculinity (HM; feelings of hostility, distrust, and insecurity combined with desire to control women) and impersonal sexuality (IS; a preference for unrestricted low commitment relationships), interact with secondary risk factors like pornography use, such that high levels of all three factors contribute synergistically to high levels of sexually aggressive attitudes (Malamuth et al., 2012) and sexually aggressive behavior (Malamuth et al., 2000). While general support for the association of foundational elements of the Confluence Model (HM and IS) with sexual aggression has accumulated (Abbey et al., 2011; Malamuth, 1986; Malamuth et al., 1991, 1995; Parkhill \& Abbey, 2008; Swartout, 2013), the specific role of pornography consumption within this model (Malamuth et al., 2000, 2012) has received less empirical study.

\section{Pornography Use in the Confluence Model}

Initial formulations of the of Confluence Model asserted that HM, involving a combination of an insecure, defensive, and hypersensitive orientation towards women as well as the desire to sexually control and dominate them (Malamuth et al., 2012), and IS, characterized as a promiscuous, unrestricted and noncommittal approach to sexuality (Malamuth et al., 2012), interact synergistically to substantially increase the risk of sexual aggression among men who are high in both factors (Malamuth et al., 1991, 1995). In subsequent development of this model, it was further argued that these “...risk factors can create a context whereby pornography 
consumption adds 'fuel to the fire,' and only when such a 'fire' exists, does pornography consumption exacerbate existing tendencies and significantly influence outcomes" (Malamuth et al., 2012, p. 429). In the context of this theory, it is argued that pornography creates, reinforces or primes, attitudes, affect and cognitions that contribute to sexual aggression (Hald \& Malamuth, 2015). While development of pornography's inclusion in this model has often emphasized the risk of "heavy pornography use" (Malamuth, 2018, p. 75), and this theory has been repeatedly tested by measuring the frequency of more general pornography use (Baer et al., 2015; Malamuth et al., 2000, 2012; Vega \& Malamuth, 2007), it has also been asserted that effects should be even more pronounced for users of explicitly sexually violent and nonconsensual materials (Malamuth, 2018; Malamuth \& Hald, 2017).

Initial findings consistent with the Confluence Model's assertion that pornography use interacts with HM and IS to predict sexual aggression were drawn from one large American college student data set collected in the 1980s (Malamuth et al., 2000, 2012) and two smaller convenience samples (Baer et al., 2015; Vega \& Malamuth, 2007). Across these studies, positive synergistic interactions were found between HM, IS, and general pornography use indicating that the positive associations between pornography use and sexually aggressive attitudes (Malamuth et al., 2012) and behavior (Baer et al., 2015; Malamuth et al., 2000) were stronger among men who were high rather than low in both HM and IS.

Since this time, further research has been conducted that is less supportive of the theorized synergistic three-way interaction between HM, IS, and pornography use that lies at the heart of Confluence Model accounts of the relationship of pornography use and sexual aggression. For example, a recent nationally representative survey of American males sought but failed to find a positive two-way synergistic interaction between IS and pornography use when 
predicting sexual aggression (Wright et al., 2021). Some may argue that this study did not properly test Confluence Model theorizing because it did not consider the three-way interaction between HM, IS, and pornography use. However, the presence of a positive two-way interaction between pornography use and IS would still indicate that pornography use synergistically increases sexual aggression among at risk men and this study was explicitly framed as a test of Confluence Model theory by its authors. Regardless, what is most interesting about this study is that while it revealed a significant interaction between exposure to "extreme pornography" (e.g., facial ejaculations, gangbangs, acts of double penetration, rough oral sex, BDSM, and coercion) and IS, the interaction was negative rather than positive. In this case, it appeared that the effects of extreme pornography use were stronger among men who were lower rather than higher in risk of sexual aggression. To be clear, it was still the case in this study that reported sexual aggression was highest among men who were high in both IS and extreme pornography use, however, this was due to a clear main effect for extreme pornography exposure rather than a particularly strong effect for extreme pornography use among high risk men. Such findings are clearly inconsistent with basic Confluence Model theorizing concerning the positive non-additive effects of sexual aggression risk factors.

The synergistic association of pornography use, HM, and IS with sexual aggression was also not found in a more thorough test of the Confluence Model that was published quite recently (Malamuth et al., 2021). In this case, HM as well as IS were included among the measures and the operationalizations of constructs were much closer to past Confluence Model research involving pornography. While a correlation clearly existed between use of "extreme pornography" (e.g., rape, BDSM, bestiality, pedophilia, and snuff) and various measures of sexual aggression and coercion, no evidence of synergistic two- or three-way interactions were 
found involving this type of pornography use (Malamuth et al., 2021). Other aspects of the Confluence Model, though, were well supported by the study's findings, including synergistic interactions between HM and IS, and between these constructs and other secondary risk factors such as low empathy, frequenting "alcohol parties," and the influence of peer-behavior that is supportive of sexual assault.

Recent studies of adolescent males have also been less supportive of the Confluence Model's theorized interaction effects of pornography use, HM, and IS. For example, one crosssectional study of adolescent males (Huntington et al., 2020) found that use of violent pornography increased the probability of reporting at least one act of contact, non-contact, and overall sexual aggression, however, this increase in probability was consistently higher among male youths who were lower rather than higher in HM. A similar pattern of results inconsistent with Confluence Model theorizing also emerged with respect to violent pornography use and IS in relation to number of acts of contact sexual aggression. To be clear, while these results indicate that use of violent pornography is certainly a positive correlate of sexual aggression in this sample, the use of such materials does not appear to uniquely exacerbate the risk of aggression among men who are otherwise at high risk in the synergistic fashion specified by the Confluence Model — in fact, the opposite may be the case.

Tests of Confluence Model predictions regarding pornography use, HM, and IS have also been examined in two recent longitudinal samples of adolescent males in Croatia (Kohut, Landripet, et al., 2020). In this case, lagged models were used to predict increases in the probability of reporting acts of sexual aggression in subsequent waves of the study. Results in these two panels suggested that only HM and not IS, pornography use, or the interactions between these variables was associated with subsequently higher odds of reporting sexual 
aggression. It is worth noting, however, that the authors acknowledged sub-optimal operationalization of HM and IS in this study, which may have undermined the analytic ability to detect interactions between these measures, pornography use, and sexual aggression.

Taken together, results regarding the synergistic effects of pornography use on sexual aggression among men who are at high in HM and IS have been mixed. Preliminary research conducted between 2000-2015 has been more supportive of this position (Baer et al., 2015; Malamuth et al., 2000, 2012; Vega \& Malamuth, 2007) while studies that have been published since that time have either failed to find the expected interactions (Kohut, Landripet, et al., 2020; Malamuth et al., 2021) or have found interactions that are effectively working in the opposite direction (Huntington et al., 2020; Wright et al., 2021) from the theorized effects. It is not clear why findings have proven to be inconsistent. While we could speculate that anything from low power, to heterogeneity of operationalizations of core constructs, to limits on the validity of the model may account for divergent findings, it would seem important to continue to test basic Confluence Model assertions about HM, IS, pornography use, and sexual aggression in multiple, broad samples, with the aim of replicating stable relationships among these constructs as they have been previously measured.

\section{Current Research}

While research is accumulating in this area, the principal supportive evidence concerning the Confluence Model's assertions about the synergistic influence of HM, IS, and pornography use on men's self-reported sexual aggression (Malamuth et al., 2000), and related attitudes (Malamuth et al., 2012), stems from two analyses of the same U.S. college student data set (Koss et al., 1987). This data was collected in 1984, well before the Internet era and the use of digital pornography by contemporary young men. In contrast, more recent evidence has been less 
consistent with Confluence Model assertions concerning positive two- and three-way interactions among, HM, IS and pornography use in association with sexual aggression (Huntington et al., 2020; Kohut, Landripet, et al., 2020; Malamuth et al., 2021; Wright et al., 2021). In an effort to identify consistent relationships concerning pornography use, HM, IS, and sexual aggression, the current series of studies began by re-examining the Confluence Model involving pornography use and sexual aggression as originally specified by Malamuth et al. (2000), using a close replication approach. Of particular theoretical interest was whether or not positive synergistic interactions between HM, IS, and general pornography use would replicate in three large samples of American and Canadian young adult men. In accord with the original formulation of the Confluence Model involving pornography use and research support (Malamuth et al., 2000, 2012) from analyses of U.S. college student data collected four decades ago (Koss et al., 1987), and our own previous findings (BLINDED FOR REVIEW), we predicted that (H1) among young adult men, pornography use would be positively associated with self-reported sexually aggressive behavior against women, but only among men who have high levels of HM and high levels of IS (i.e., there should be a three-way interaction between HM, IS, and pornography use). This hypothesis was tested in three large independent samples. The measures of HM, IS, and sexual aggression used in the current studies closely follow those outlined in Malamuth et al. (2000). Pornography use, however, is a complex behaviour which we did not feel was well represented by the approach used in the original Malamuth et al (2000) study because it was limited to the assessment of use of nine specific pornographic magazines (e.g., Playboy, Penthouse, Chic, Club, Forum, Gallery, Genesis, Oui, and Hustler). Although such an item may have been appropriate in the 1980s and reflected typical pornography use behavior at that time, in the current age, pornography use can occur across both digital and analog sources, and the 
magazines described by this item are either no longer in publication or have very small circulation rates. We consequently decided to add an additional measure of pornography use that is not tied to a specific type of media. The pre-registered (BLINDED FOR REVIEW) — analytic plan for these studies also replicated Malamuth et al.'s OLS regression approach, though departures from this plan were adopted when evidence of violated assumptions became apparent.

\section{Method}

Details of the outlined rationale, methodology, measures, data analytic plan, as well as data and syntax for testing the Confluence Model can be found at https://bit.ly/3eRRejm for Study 1, and at https://bit.ly/2yFaPma for Studies 2, and 3.

\section{Participants and procedure.}

\section{Study 1: Mechanical Turk Sample}

Participants for this study were recruited from Amazon's Mechanical Turk (MTurk) and restricted to North American males 18-24 years of age who were fluent in English and who had a HIT approval rate of more than $97 \%$ (i.e., $97 \%$ of the previous tasks participants had attempted on MTurk were completed). The pre-registered recruitment plan for this sample involved a sequential analysis approach (Lakens, 2014). Sequential analysis is a statistical method for analyzing data while it is being collected. Adjustments are made for inflated Type 1 error and analyses cease with a pre-defined stopping rule. This method was employed in an effort to reduce the financial cost of running a large sample study on a limited budget. In this case, the hypothesis was first tested at a pre-specified cut-point of $N=1,000$ participants. This cut point was not determined by power considerations. Available funding provided for the recruitment of approximately 2,000 participants if necessary and past research had reported the target effects with sample sizes of $N=183$ (Baer et al., 2015), and $N=2,652$ (Malamuth et al., 2000) men 
respectively. This preliminary test (at $N=1000$ ) failed to find expected significant interactions between HM, IS, and pornography use in association with self-reported sexual aggression. Consequently, we continued to recruit participants until we exhausted recruitment funds available for this sample. Of the 2,103 consenting participants who provided data, a total $n=575$ were excluded from the analytic sample for (a) failing to meet eligibility criteria $(n=222)$; (b) failing one of two attention checks $(n=290)$; or $(c)$ indicating homosexual or MSM sexual orientation on a categorical measure $(n=63)$. Same-sex attracted men were excluded from this study because the Confluence Model, with its specific focus on hostility towards women, was created with the intent of explaining men's sexual aggression against women. Malamuth et al.'s (2000) classic study, which we were seeking to replicate, also excluded same-sex attracted men from analysis. We note, however, that our analyses included explicitly bisexual and pansexual identified men, as we believed they would be more likely to have had sexual experiences with women. Participants who were excluded for failing to meet attention checks did not differ significantly from included cases on any demographic characteristic or focal variables of interest in this study.

The resulting analytic sample $(N=1,528)$ was primarily composed of American $(98.49 \%$; $n=1505)$ Caucasians $(72.19 \% ; n=1,103)$ with some post-secondary education $(82.59 \% ; n=$ 1,266). Participants were typically in close romantic and sexual relationships $(61.32 \% ; n=937)$, generally non-religious $(51.11 \%, n=781)$, and had a mean age of $M=22.46(S D=1.49)$.

\section{Table 1}

Demographic Characteristics

\begin{tabular}{cccc}
\hline & $\begin{array}{l}\text { Study 1 } \\
(\% / M)\end{array}$ & $\begin{array}{l}\text { Study 2 } \\
(\% / M)\end{array}$ & $\begin{array}{c}\text { Study 3 } \\
(\% / M)\end{array}$ \\
\hline Race / Ethnicity & & & \\
Asian & 8.05 & 10.30 & 5.86 \\
Black & 7.33 & 12.49 & 9.06 \\
Caucasian & 72.19 & 51.86 & 65.19
\end{tabular}




$\begin{array}{lccc}\text { Latino } & 6.87 & 2.10 & 2.10 \\ \text { South Asian } & 1.24 & 12.96 & 5.19 \\ \text { Others } & 4.32 & 10.60 & 12.60\end{array}$

Highest Education

Trade School Certificate,

Highschool, or Less

$\begin{array}{lll}36.13 & 55.48 & 62.32\end{array}$

College Degree / Diploma

59.62

42.90

35.91

Graduate Degree

4.25

1.62

1.77

Religion

Agnostic / Atheist 49.93

37.18

43.72

Buddhist

1.70

2.21

1.11

Christian

41.43

43.61

43.49

Hindu

0.85

4.80

1.67

Jewish

1.51

0.86

1.11

Muslim

1.05

7.59

3.23

Others

3.53

3.75

6.12

Heterosexual Orientation

92.74

89.70

90.17

Currently in a Relationship

61.32

47.86

50.17

Age (mean years)

22.46

20.89

21.66

\section{Study 2 and Study 3: Canadian Student and Non-Student Samples}

Quota samples of Canadian young men aged 18-24 who were currently enrolled (Study

2) or currently not enrolled (Study 3) in postsecondary education were recruited simultaneously from a panel maintained by Leger Marketing Inc. A panel is a group of individuals who have provided basic demographic information and agreed to be contacted in the future to participate in survey research. Leger Marketing Inc. was tasked with the recruitment of two large samples of approximately 1,000 participants each who were regionally representative (by province) of Canadian males between 18-24 years of age. To this end, a sampling frame of Canadian males based on age and region of residence was used to guide electronic solicitations to participate in an online survey. Quota sampling was then used to ensure that characteristics of the recruited sample matched the parameters of the sampling frame. 
The study survey platform for Study 2 and Study 3 was accessed 12,854 times by 10,493 unique panel members. When more than one record existed for a panel member, we retained the most complete record that was recorded earliest for analytic purposes and discarded the other records. Of $n=4,355$ participants who consented to participate and provided data, $n=2,401$ were removed from the analytic sample for failing to meet eligibility criteria $(n=496)$; not providing data on focal measures $(n=356)$; failing one of two attention checks $(n=1,398)$; and indicating homosexual or MSM sexual orientation, or failing to indicate a sexual orientation on a categorical measure ( $n=151)$. Unlike Study 1, participants who were excluded for failing the attention checks were notably different from the analytic sample on several focal variables (see Table 2). To ensure that data exclusions were not unduly influencing our results, once the planned analyses were run, negative binomial regressions were re-rerun using a combined dataset that included the entire analytic samples across these two studies, all data that were excluded for failing attention checks, and all cases where missing data could be imputed (40 datasets were imputed using the mice package in R;van Buuren \& Groothuis-Oudshoorn, 2011). Results were broadly in agreement with those described below (Analytic syntax, data, and results for these supplementary analyses can be found at https://bit.ly/39VojqM).

Table 2

Excluded Case Comparisons

\begin{tabular}{lccc}
\hline & $\begin{array}{c}\text { Retained } \\
(\% / M)\end{array}$ & $\begin{array}{c}\text { Excluded } \\
(\% / M)\end{array}$ & $\begin{array}{c}\text { Effect Size } \\
(r)\end{array}$ \\
\hline Categorical Variables & & & \\
$\quad$ French Language Survey & 16.94 & 41.31 & 0.32 \\
Any Sexual Aggression & 38.29 & 61.77 & 0.24 \\
Muslim & 5.57 & 12.18 & 0.23 \\
Living in Quebec & 24.46 & 42.98 & 0.23 \\
Non-Religious & 40.21 & 25.84 & 0.18 \\
White Race & 58.03 & 47.88 & 0.11 \\
Hindu & 3.35 & 4.83 & 0.11 \\
More than high school & & & \\
education & 47.65 & 55.65 & 0.09
\end{tabular}


Not currently enrolled in post-secondary education In a close romantic relationship

$$
46.32
$$

Continuous Variables

Hostility towards women

PMU

CPU

Negative masculinity

Age of first intercourse (reversed and recoded)

Number of sex partners

$\begin{array}{ccc}4.38 & 6.22 & 0.30 \\ 1.23 & 1.47 & 0.19 \\ 4.87 & 4.27 & 0.15 \\ 2.33 & 2.52 & 0.12 \\ & & \\ 6.64 & 6.90 & 0.05 \\ 4.14 & 4.44 & 0.03 \\ 21.25 & 21.11 & 0.03\end{array}$

$39.79 \quad 0.07$

$51.51 \quad 0.00$

Age

21.25

21.11

0.03

Notes. Ranges for continuous variables were: $0-15$ for hostility towards women; 1-4 for pornographic magazine use (PMU); 1-8 for contemporary pornography use (CPU); 1-5 for negative masculinity; 1-10 for age of first intercourse; 1-15 for number of sex partners; and 18-24 for age.

The final Canadian analytic sample $(n=1,954)$ was divided into participants who were currently enrolled in post-secondary education (Study $2 ; n=1,049$ ) and participants who were not currently enrolled in post-secondary education (Study $3 ; n=905$ ). Compared to nonstudents, students were less likely to be Caucasian $\left(51.86 \%\right.$ vs. $\left.65.19 \% ; \chi^{2}(1)=35.47, p<.001\right)$. Both groups were modally Christian (43.56\%), though students were more likely to be Muslim $\left(7.59 \%\right.$ vs. $\left.3.23 \% ; \chi^{2}(1)=17.47, p<.001\right)$ and Hindu $\left(4.80 \%\right.$ vs. $1.67 \% ; \chi^{2}(1)=14.64, p<$ $.001)$, and less likely to be non-religious $\left(37.18 \%\right.$ vs. $\left.43.72 \% ; \chi^{2}(1)=8.58, p=.003\right)$ than nonstudents. Mean age also differed between groups, with the student sample being almost a year younger on average than the non-student sample $(M=20.89$ vs. $M=21.66 ; t(1872)=8.47, p<$ .001). Almost half of the participants were in close romantic and sexual relationships (48.93\%).

\section{Materials for Studies 1, 2 and 3}

Assessment of HM, IS, and sexual aggression closely followed the description found in Malamuth et al. (2000). Assessments of these measures took place in English in the Mechanical Turk sample. Participants in the Canadian student and non-student samples had the option of 
completing measures in either French or English. To this end, Leger Marketing's translation service was employed to conduct forward and backward translations. A small number of mistranslations were identified by the first author and corrected (copies of the French translations are available here: https://osf.io/2vgfw/?view_only=75cca0e7af764cb3a73355e2a16577dd). A minority of student $(17.54 \% / n=184)$ and non-student $(16.24 \% / n=147)$ participants opted to take the survey in French, and a comparison of responses between those who took the English and French suggested that each of the following scales had similar psychometric properties (e.g., internal-consistencies and factor loadings were similar).

Hostile masculinity. Following Malamuth et al. (2000), the measure of HM was an aggregate composed of negative masculinity (Malamuth, 2017; Malamuth et al., 2000) and hostility towards women (Check, 1984). Negative masculinity was measured with 9 items (e.g., "I remind myself that I'm 'number one' and have to look out for myself first") using 5-point scales ranging from 1 - "Not at all like me" to 5 - "Very much like me." Responses were mean aggregated (Study 1, $\alpha=.81$; Study $2 \alpha=.83$; Study 3, $\alpha=.81$; EFA with ML indicated one predominant factor across all samples). In Study 1, hostility towards women was measured with 30 dichotomous True/False items (e.g., "Many times a woman appears to care, but just wants to use you.") that were summed with reverse coding where necessary (Study 1, $\alpha=.87$; EFA with ML indicated one factor). In the Studies 2 and 3, hostility towards women was measured with 15 of the original 30 items to reduce the length of the survey (Study 2, $\alpha .=.71$; Study $3, \alpha=.69$; EFA with ML indicated two factor solutions across both samples). These items were chosen for having the highest item-total correlations in Study 1 and re-analysis of this sample using a hostile masculinity score that was restricted to these items did not change the results of Study 1 appreciably. Negative masculinity was correlated with hostility towards women in Study 1, $r=$ 
$.41, p<.001$, Study 2, $r=.25, p<.001$, and Study 3, $r=.29, p<.001$. Within each sample, both variables were standardized, mean aggregated, and re-standardized so that higher scores represented higher HM.

Impersonal sexuality. Following Malamuth et al. (2000), our measure of IS consisted of participants' age of first intercourse combined with their reported number of sexual partners. Age of first intercourse was assessed with an open-ended single item, "How old were you when you first had voluntary sexual intercourse?" Consistent with the operational definitions of past Confluence Model studies involving pornography use (Baer et al., 2015; Kohut, Landripet, et al., 2020; Malamuth et al., 2000), current age was substituted for age of first intercourse among participants who had yet to have intercourse. Responses were recoded into 10 categories so that lower scores represented a higher age of first intercourse. Recoded responses ranged from 1 "first intercourse at age 23 and over" to 10 - "first intercourse at age 14 and under." Number of sexual partners was assessed with a single open-ended item, "How many sexual intercourse partners have you had since age 14?" and responses were recoded into 15 approximately equalsized categories ranging from 0 - "No sexual partners" to 14 - "33 or more sexual partners. A 10 category approach for number of sexual partners, as per Malamuth et al. (2000), was also examined, but the use of 15 categories produced groups of more comparable sizes and improved the correlation of this item with sexual aggression. Recoded age of first intercourse was correlated with recoded number of sexual partners, in Study $1, r=.57, p=.001$, Study $2, r=.51$, $p=.001$, and Study 3, $r=.51, p=.001$. Within each sample, both variables were standardized, mean averaged, and re-standardized.

Sexual aggression. Following Malamuth et al. (2000), sexual aggression was measured using 10 items from the Sexual Experiences Survey (Koss \& Oros, 1982). Participants responded 
to items (e.g., "Since the age of 14, how many times have you been in a situation where you used some degree of physical force (twisting her arm, holding her down, etc.) to try to make a woman engage in kissing or petting when she didn't want to?”), with 6-point scales ranging from 0 - “0 times" to 5 - "5 or more times) that were summed so that higher scores indicated more acts of sexual aggression (Study 1, $\alpha=.90 ;$ Study 2, $\alpha=.90$; Study 3, $\alpha=.91$; EFA with ML indicated one predominant factor across all samples).

Pornography use. The following studies employed two measures of pornography use. To replicate Malamuth et al. (2000), pornographic magazine use (PMU) was assessed with a single item (e.g., "How often do you read any of the following magazines: Playboy, Penthouse, Chic, Club, Forum, Gallery, Genesis, Oui, Hustler?’) with four labeled response options ranging from 1 - "Never" to 4 - "Very frequently." Relatively few men in Study 1 (27.75\%), Study 2 (16.68\%), and Study $3(18.90 \%)$ reported any use of these magazines. Further, modal frequency of use among magazine users was "Seldom" across all three studies $(83 \%, 76.02 \%, 75.40 \%$ of magazine users respectively). A negative reciprocal function was applied to magazine use scores to adjust for positive skew though similar results were found when raw untransformed scores were analyzed instead. Malamuth et al.'s (2000) measure of PMU, based on a data set collected in 1984, does not assess the use of Internet-based video, pictorial, or textual pornography, which is a common form of pornography consumption by young men today. To improve face-validity and comprehensiveness we measured contemporary pornography use (CPU) across both internet and non-internet media with Kohut et al.'s $(2017,2018)$ assessment approach. Participants were first instructed that "“using pornography' means intentionally looking at, reading, or listening to: (a) pictures or videos of nude individuals, (b) pictures or videos in which people are having sex, or (c) written or audio material that describes nude individuals, or people having sex," and that, 
"[viewing] or interacting with actual, live, nude individuals (in person or online), or participating in interactive sexual experiences with other human beings (in person or online) are not considered 'using pornography'." Participants were then asked to respond to a single item (e.g., "How frequently do you use pornography while alone (i.e., without a partner)?" using an 8-point scale that had the following response options: "Never"; "Almost never"; "Less than once a month"; "One to 3 times a month"; "One to 2 times per week"; "3 to 4 times per week"; "About once a day"; and "More than once a day."1 Interestingly, these measures of pornography use were uncorrelated with one another across all three samples ( $r$ ranged from -.02 to .04), indicating that these measures likely reflect different constructs. Responses to both single item measures were independently standardized and analyzed separately.

Procedure. Across Studies 1, 2, and 3, participation occurred online. After completing informed consent procedures, participants were asked to respond to a series of demographic items, followed by assessments of their pornography use, acts of sexual aggression, IS, and HM. Assessments of sex drive, Dark Tetrad traits (Machiavellianism, narcissism, psychopathy, and sadism), sociosexual orientation, attitudes towards violence, likelihood of sexual aggression, and attitudes towards women were also completed. Median duration of survey participation was 19 minutes. Because Studies 1, 2, and 3 focus on testing the Confluence Model hypothesis concerning HM, IS, pornography use, and sexual aggression, results of analyses of other parameters will be reported in separate publications. Two attention check items were also embedded in the survey to identify and remove inattentive participants (Hauser \& Schwarz, 2016). The Mechanical Turk participants were largely post-screened based on their responses to

\footnotetext{
${ }^{1}$ We note that pornography use with a partner was also assessed in these studies, though this behavior is comparatively infrequent and conceptually distinct from solitary pornography use (Kohut, Balzarini et al., 2020). We also assessed the use violent and coercive sexual media. While this is of clear relevance to the Confluence Model, we wish to examine it comprehensively in a separate report.
} 
demographic and attention check items while student and non-student samples were both prescreened for demographic suitability before informed consent, and post-screened using subsequent responses to the survey items and attention checks. Participants in Study 1 (Mechanical Turk) were compensated with \$1.00 USD in Amazon credit. Participants in Studies 2 (Canadian students) and 3 (Canadian non-students) were given either \$2.00 CAD, 4 Air Miles frequent flyer miles, or 50 Aeroplan frequent flyer miles (chosen by the participant) as well as 4 entries for a monthly draw where prizes included an iPad, a prize of $\$ 100 \mathrm{CAD}$, and a prize of $\$ 1,000$ CAD. All procedures were reviewed and approved by the research ethics board at (BLINDED FOR REVIEW) prior to the recruitment of these samples. We report all manipulations, measures, and exclusions in these studies

\section{Analytic Plan}

The data from Study 1 were analyzed before recruitment began for Studies 2 and 3, and the results of this analysis informed our analytic plan for the subsequent samples. The analytic plan for the Study 1 was a variation of the ordinary least squares (OLS) regression used in previous Confluence Model research (Baer et al., 2015; Malamuth et al., 2000; Vega \& Malamuth, 2007), where self-reported sexual aggression was first regressed on standardized HM, IS, and their interaction. In a separate second step, standardized pornography use and all twoand three-way interactions involving pornography use were added to the model. In this second analytic model, support for the assertion that pornography is positively associated with sexual aggression among men who had high scores on both the HM and IS measures would be indicated by a positive three-way interaction between pornography use, HM, and IS, accompanied by three positive two-way interactions between HM, IS, and pornography use, and positive main effects 
for pornography use, HM, and $\mathrm{IS}^{2}$. Positive two-way interactions between pornography use and either HM or IS in the absence of a three-way interaction, while not wholly consistent with the role of pornography use among men who are high in both HM and IS, could also be taken as indicating other patterns of pornography-related "confluence." The presence of a positive twoway interaction between HM and IS in the absence of a three-way interaction between all three predictor variables is irrelevant with respect to Confluence Model predictions involving pornography use. However, on its own, the interaction between HM and IS still supports a "core" Confluence Model prediction regarding the synergistic influence of these two "primary" risk factors for sexual aggression. Note that while recruitment was underway for Study 1, we derived an estimated effect size from a $p$-value reported in Malamuth et al. (2000), and then used that to calculate the weighted mean effect size, $f^{2}=0.0074$, of the three-way interactions reported in Malamuth et al. (2000) and Baer et al. (2015). With this effect size, $N=837$ participants are needed to achieve $80 \%$ power with a one-tailed $\alpha=.05$ in a regression model with 7 predictors. Importantly, however, inspection of the residuals of the OLS regression analysis in Study 1 indicated that the assumptions of normality and linearity of the residuals were violated. A review of the distributions of all variables within this sample indicated high kurtosis (14.91) and positive skewness (3.53) in the measure of sexual aggression. The published literature confirms that the distributions of measures of sexual aggression often depart from normality, and for this reason, Swartout et al. (2015) previously recommended the use of negative binomial regression rather than OLS regression when analyzing data concerning sexual aggression and similarly

\footnotetext{
${ }^{2}$ Some may believe that Confluence Model predictions are more clearly supported by a regression model consisting of significant main-effects for HM and IS, a significant two-way interaction between HM and IS, and a significant three-way interaction between HM, IS and pornography use. Such a regression model only supports Confluence Model predictions, however, under conditions where measures of HM, IS and pornography use range from $0 \rightarrow+\infty$. When variables are mean centered or standardized, the relevant model must be adjusted by adding a main effect for pornography use, and two-way interactions between HM and pornography use and IS and pornography use, to make equivalent predictions. Mathematical justification is available from the first author.
} 
distributed data. Consequently, we re-analyzed responses from this sample with negative binomial regression. In a negative binomial regression, support for Confluence Model theorizing would be indicated by main effects of HM, IS, and pornography use. This is the case because in negative binomial models, the $\log$ of the dependent variable is expressed as a liner combination of predictor variables. As a consequence, one unit change in predictor variables results in exponential change in the expected value of the dependent variable and the joint impact of two or more main-effects have compounded exponential effects on the dependent variable (even in the absence of interactions between them). However, the mechanics of non-linear compounding in negative binomial regressions were not apparent to us at the outset of the analysis, so we also included potential interactions between HM, IS, and pornography use in our negative binomial models.

For subsequently collected Study 2 and Study 3 data, we pre-registered the analysis of the Confluence Model hypothesis using a negative binomial regression appropriate for statistical analysis of skewed count data (Swartout et al., 2015) as well as an OLS regression for comparison purposes. Figures were made with the plotly package in $R$ (Sievert, 2020).

\section{Results}

As can be seen in Table 3, self-reported sexual aggression was positively correlated with HM, IS, and pornographic magazine use (PMU) across Studies 1 through 3. In contrast, contemporary pornography use (CPU) was not correlated with sexual aggression in Study 1 or Study 2 but was weakly positively correlated with sexual aggression in Study 3.

Table 3 Correlations between Sexual Aggression and its Confluence Model Predictors Across All Three Studies

$$
\text { Sample } 1 \quad \text { Study } 2 \quad \text { Study } 3
$$

(Mechanical Turk) (Canadian Students) (Canadian Non-Students)

HM .37** .35** $31 * *$




\begin{tabular}{lccc} 
IS & $.25 * *$ & $.28 * *$ & $.28 * *$ \\
PMU & $.33^{* *}$ & $.49 * *$ & $.42 * *$ \\
CPU & .03 & -.02 & $.07 *$ \\
\hline
\end{tabular}

Note.

* Correlation is significant at the 0.05 level (2-tailed).

** Correlation is significant at the 0.001 level (2-tailed).

OLS Regressions. When sexual aggression was regressed on HM, IS, and their interaction, the proportion of variance explained was $R^{2}=.197$ in Study $1, R^{2}=.225$ in Study 2, and $R^{2}=.167$ in Study 3, and in each case, all predictors had significant positive associations with sexual aggression. Importantly, these findings replicate core Confluence Model theorizing with respect to the synergistic interaction between these two primary risk factors of sexual aggression.

When predictors involving PMU were added to this model, significant increases in $R^{2}$ were found in all three studies: Study $1, \Delta R^{2}=.090, F(4,1520)=47.91, p<.001$, Study $2, \Delta R^{2}=$ $.174, F(4,1041)=75.41, p<.001$, and Study $3, \Delta R^{2}=.112, F(4,897)=34.95, p<.001$. These regression models (see Table 4; Figure 1) indicated significant positive main effects for PMU across all three samples: Study $1, \beta=0.19, p<.001$; Study $2, \beta=1.81, p<.001$; and Study $3, \beta$ $=1.87, p<.001$. These main effects were qualified by a significant two-way interaction between HM and PMU in Study $1, \beta=0.20, p<.001$, and both a positive two-way interaction between HM and PMU, $\beta=1.18, p<.001$ as well as the expected positive three-way interaction, $\beta=$ $0.42, p=.012$, in Study 2 .

\section{Table 4}

Results of Ordinary Least Squares Regression Approach Predicting Sexual Aggression with PMU

\begin{tabular}{|c|c|c|c|c|c|c|c|c|}
\hline \multirow[b]{2}{*}{ Parameter } & \multicolumn{3}{|c|}{$\begin{array}{c}\text { Study } 1 \\
\text { (Mechanical Turk) }\end{array}$} & \multicolumn{3}{|c|}{$\begin{array}{c}\text { Study } 2 \\
\text { (Students) }\end{array}$} & \multicolumn{2}{|c|}{$\begin{array}{c}\text { Study } 3 \\
\text { (Non-Students) }\end{array}$} \\
\hline & $\beta$ & Sig. & $s r^{2}$ & $\beta$ & Sig. & 2 & Sig. & $s r^{2}$ \\
\hline
\end{tabular}




\begin{tabular}{|c|c|c|c|c|c|c|c|c|c|}
\hline HM & 0.30 & $<.001$ & .08 & 0.21 & $<.001$ & .04 & 0.17 & $<.001$ & .02 \\
\hline IS & 0.15 & $<.001$ & .02 & 0.15 & $<.001$ & .02 & 0.17 & $<.001$ & .03 \\
\hline HM x IS & 0.11 & $<.001$ & .01 & 0.04 & .132 & .00 & 0.09 & .006 & .01 \\
\hline PMU & 0.19 & $<.001$ & .03 & 0.28 & $<.001$ & .06 & 0.29 & $<.001$ & .05 \\
\hline HM x PMU & 0.20 & $<.001$ & .04 & 0.22 & $<.001$ & .03 & 0.04 & .194 & .00 \\
\hline IS x PMU & 0.01 & .723 & .00 & 0.03 & .280 & .00 & 0.05 & .190 & .00 \\
\hline $\begin{array}{l}\text { HM x IS x } \\
\text { PMU }\end{array}$ & 0.02 & .411 & .00 & 0.08 & .012 & .00 & 0.06 & .144 & .00 \\
\hline $\begin{array}{c}\Delta R^{2} \\
95 \mathrm{CIs} \\
\left(R^{2}\right)\end{array}$ & $\begin{array}{c}.090 \\
{[.063, .117} \\
] \\
(.289)\end{array}$ & $<.001$ & & $\begin{array}{c}.174 \\
{[.132, .216} \\
] \\
(.395)\end{array}$ & $<.001$ & & $\begin{array}{c}.112 \\
{[.073, .151} \\
] \\
(.279)\end{array}$ & $<.001$ & \\
\hline
\end{tabular}
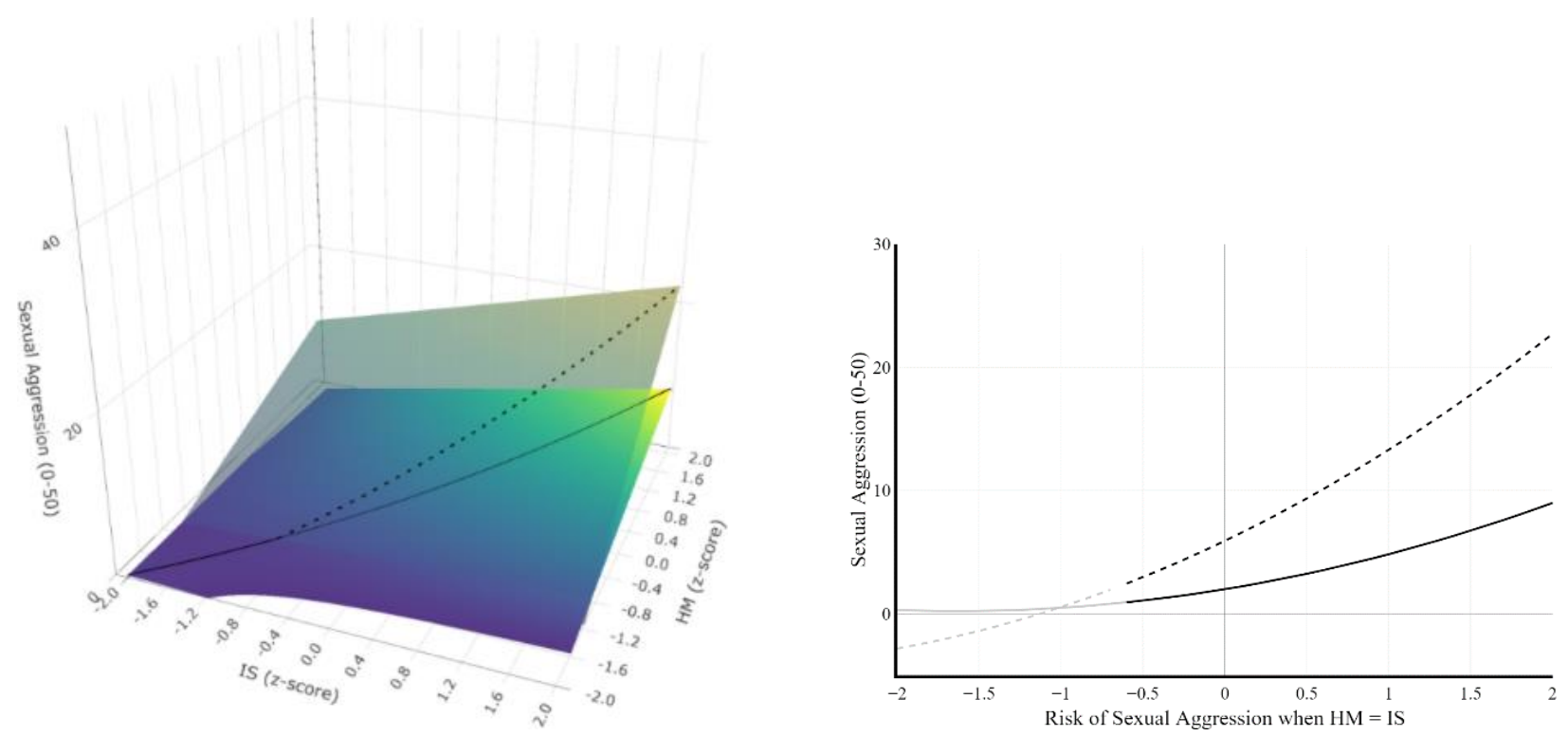

Figure 1a. Study 1: Mechanical Turk sample $(N=1,528)$

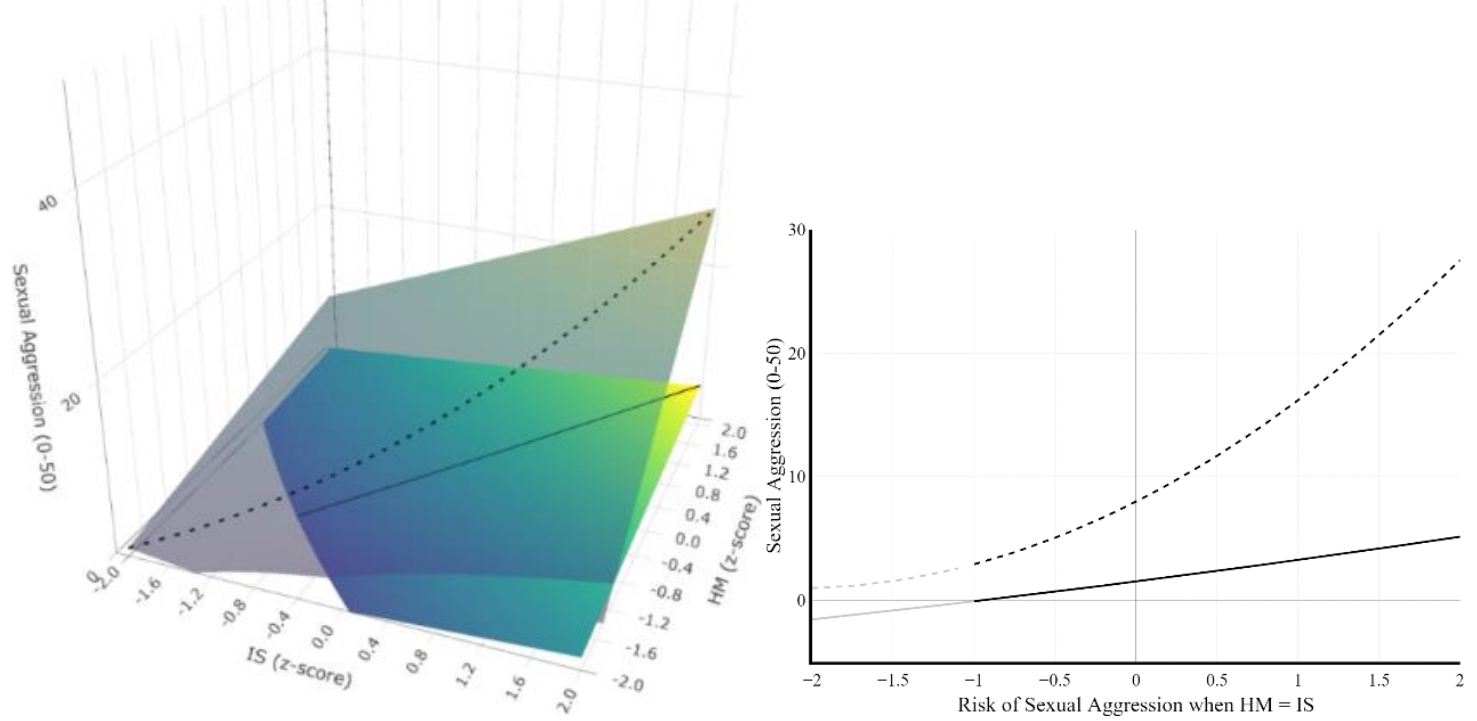


Figure 1b. Study 2: Canadian student sample $(N=1,049)$
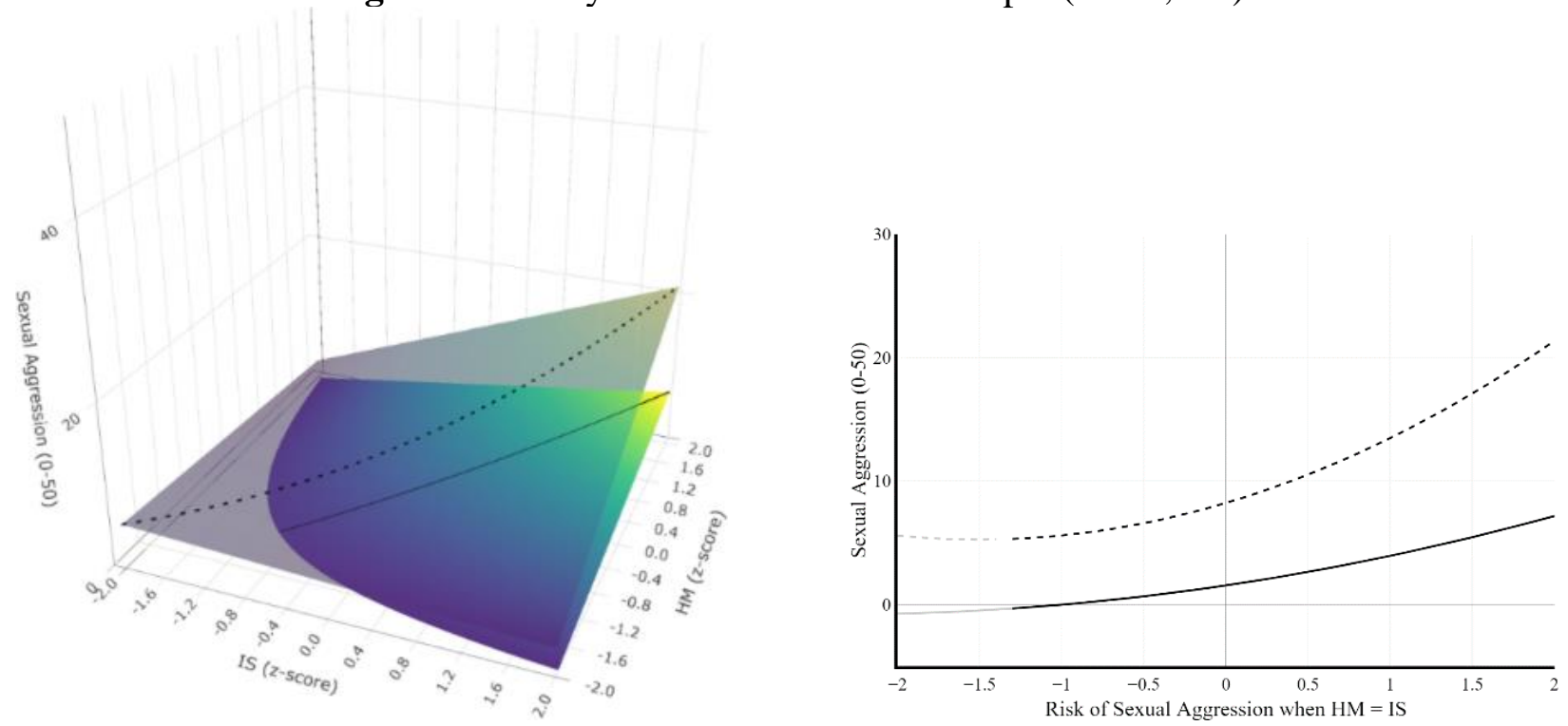

Figure 1c. Study 3: Canadian non-student sample $(N=905)$

Figure 1. Figures 1a-c plot the OLS regression results for PMU from Studies 1-3. Opaque surfaces and solid lines depict predictions for "never" using pornography while transparent surfaces and hashed lines depict predictions for using pornography "very frequently." The lefthand panels provide an overview of the prediction space while the right-hand panels focus on the simple main effects of PMU when HM = IS (gray lines indicate regions of non-significance). Tests of simple main effects of PMU when HM = IS support Confluence Model theorizing concerning the synergistic risk of pornography use among at risk men in Studies 1 and 2.

Supporting Confluence Model theorizing in Studies 1 and 2, tests of simple main effects for PMU when HM = IS indicated that PMU was positively associated with sexual aggression among men who are high in both HM and IS but not among men low in these characteristics (see Figure 1a-b, right-hand panels). In Study 3, the absence of significant interaction terms involving pornography use indicated that users of pornographic magazines generally reported more aggression across the range of HM and IS and that the magnitude of this association did not vary more than would be expected by chance (see Figure 1c).

Results when the measure of CPU was tested were quite different from those involving the measure of PMU. The addition of predictors involving CPU significantly increased the $R^{2}$ in Study $2, \Delta R^{2}=.013, F(4,1041)=4.598, p=.001$, but not in Study $1, \Delta R^{2}=.004, F(4,1520)=$ 
$1.92, p=.105$, or Study $3, \Delta R^{2}=.006, F(4,897)=1.59, p=.176$. A significant negative main effect for CPU, $b=-0.52, p=.005$ and a significant positive 3-way interaction between HM, IS, and CPU was, $b=0.28, p=.035$ found in Study 2. No further predictors involving CPU were significantly associated with sexual aggression in this sample (see Table 5 \& Figure 2).

Table 5

Results of Ordinary Least Squares Regression Approach Predicting Sexual Aggression with $C P U$

\begin{tabular}{|c|c|c|c|c|c|c|c|c|c|}
\hline \multirow[b]{2}{*}{ Parameter } & \multicolumn{3}{|c|}{$\begin{array}{c}\text { Study } 1 \\
\text { (Mechanical Turk) }\end{array}$} & \multicolumn{3}{|c|}{$\begin{array}{c}\text { Study } 2 \\
\text { (Students) }\end{array}$} & \multicolumn{3}{|c|}{$\begin{array}{c}\text { Study } 3 \\
\text { (Non-Students) }\end{array}$} \\
\hline & $\beta$ & Sig. & $s r^{2}$ & $\beta$ & Sig. & $s r^{2}$ & $\beta$ & Sig. & $s r^{2}$ \\
\hline $\mathrm{HM}$ & 0.34 & $<.001$ & .12 & 0.34 & $<.001$ & .11 & 0.25 & $<.001$ & .06 \\
\hline IS & 0.19 & $<.001$ & .03 & 0.25 & $<.001$ & .06 & 0.22 & $<.001$ & .05 \\
\hline HM x IS & 0.15 & $<.001$ & .02 & 0.19 & $<.001$ & .04 & 0.13 & $<.001$ & .02 \\
\hline $\mathrm{CPU}$ & - & - & - & -0.08 & .005 & .01 & - & - & \\
\hline $\mathrm{HM}$ x CPU & - & - & - & 0.02 & .401 & .00 & - & - & \\
\hline IS x CPU & - & - & - & -0.02 & .397 & .00 & - & - & \\
\hline $\mathrm{HM} \times \mathrm{IS} \times \mathrm{CPU}$ & - & - & - & 0.10 & $<.001$ & .01 & - & - & \\
\hline $\begin{array}{c}\Delta R^{2} \\
95 \% \mathrm{CIs} \\
\left(R^{2}\right)\end{array}$ & $\begin{array}{c}.004 \\
{[-.002, .013]} \\
(.199)\end{array}$ & .105 & & $\begin{array}{c}.013 \\
{[.000, .026]} \\
(.238)\end{array}$ & .019 & & $\begin{array}{c}.006 \\
{[-.004, .015]} \\
(.172)\end{array}$ & .176 & \\
\hline
\end{tabular}
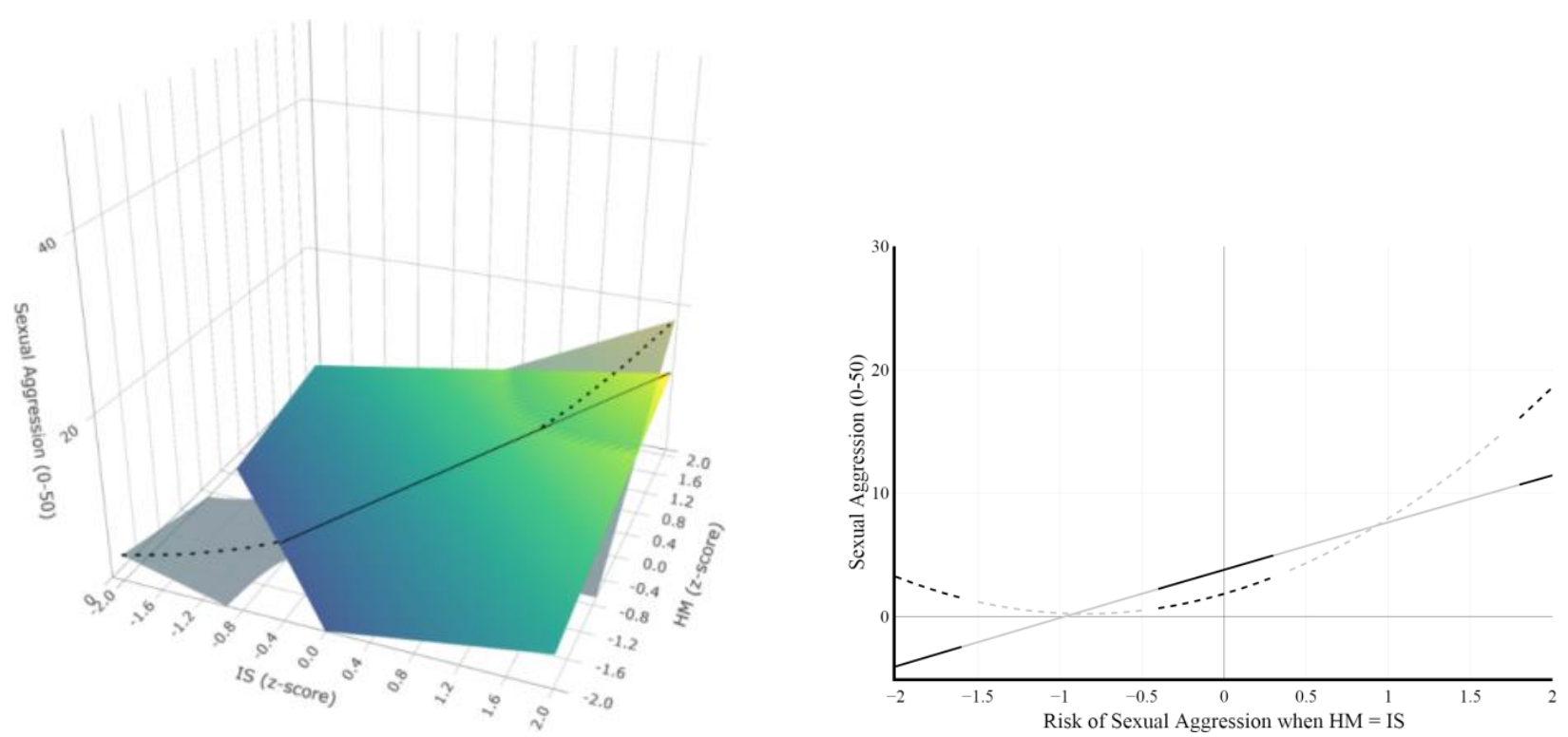

Figure 2. Study 2: Canadian student sample $(N=1,049)$ 
Figure 2. This figure plots the OLS regression results CPU from Study 2. The opaque surface and solid line depict predictions for "never" using pornography while transparent surface and hashed line depict predictions for using pornography "more than once a day." The left-hand panel provides an overview of the prediction space while the right-hand panel focuses on the simple main effects of CPU when HM = IS (gray lines indicate regions of non-significance). Tests of simple main effects of CPU when HM = IS do not support Confluence Model theorizing. CPU increases the risk of self-reported sexual aggression among men who are high in HM and IS as well as men who are low in HM and IS. Moreover, CPU decreases risk of selfreported sexual aggression among men with mean levels of HM and IS. Unlike analyses involving PMU, omnibus tests of the associations between CPU on sexual aggression were not significant in Studies 1 and 3.

In contrast to Confluence Model hypotheses, tests of simple main effects for pornography use when HM = IS in Study 2 indicated that pornography use was positively associated with sexual aggression among men who are both high and low in HM and IS, and negatively associated with sexual aggression among men near the mean of both HM and IS (see Figure 2, right-hand panel).

Negative binomial regressions. In our initial models, we first found consistent positive main effects for HM and IS across the three studies (results not shown). Loglikelihood ratio tests (LRTs) indicated that adding components involving PMU to negative binomial regression models consisting of HM, IS, and their interaction, significantly improved the model fit across all three studies: Study 1, $\chi^{2}(4)=64.07, p<.001$; Study $2, \chi^{2}(4)=109.28, p<.001$; and Study 3, $\chi^{2}(4)=112.18, p<.001$. This improvement in fit was largely driven by significant positive main effects across all three studies: Study $1, b=0.27, p<.001$, IRR $=1.31$; Study $2, b=0.62, p<$ .001, IRR $=1.86 ;$ and Study $3, b=0.61, p<.001$, IRR $=1.85$. These significant main effects, in the presence of significant positive main effects for HM and IS indicate a degree of non-linear synergy between these predictor variables. Specifically, each unit increase in PMU produces larger linear changes in self-reported sexual aggression among men who are high in both HM 
and IS than men who are low in HM and IS. However, significant interactions further qualified the expected pattern of "confluence" differently in each of the studies (see Table 6 \& Figure 4).

Table 6

Results of the Negative Binomial Regression Approach Predicting Sexual Aggression with $P M U$

\begin{tabular}{|c|c|c|c|c|c|c|c|c|c|}
\hline \multirow[b]{2}{*}{ Parameter } & \multicolumn{3}{|c|}{$\begin{array}{c}\text { Sample 1 } \\
\text { (Mechanical Turk) }\end{array}$} & \multicolumn{3}{|c|}{$\begin{array}{l}\text { Study } 2 \\
\text { (Students) }\end{array}$} & \multicolumn{3}{|c|}{$\begin{array}{c}\text { Study } 3 \\
\text { (Non-Students) }\end{array}$} \\
\hline & $b$ & $\operatorname{Exp}(b)$ & Sig. & $b$ & $\operatorname{Exp}(b)$ & Sig. & $b$ & $\operatorname{Exp}(b)$ & Sig. \\
\hline HM & 0.74 & 2.10 & $<.001$ & 0.70 & 2.01 & $<.001$ & 0.73 & 2.07 & $<.001$ \\
\hline IS & 0.51 & 1.67 & $<.001$ & 0.87 & 2.39 & $<.001$ & 0.87 & 2.39 & $<.001$ \\
\hline HM x IS & -0.07 & 0.94 & .218 & -0.23 & 0.79 & .004 & -0.15 & 0.86 & .107 \\
\hline PMU & 0.27 & 1.31 & $<.001$ & 0.62 & 1.86 & $<.001$ & 0.61 & 1.85 & $<.001$ \\
\hline HM x Porn & 0.19 & 1.20 & .001 & -0.06 & 0.94 & .349 & -0.20 & 0.82 & .001 \\
\hline IS $x$ Porn & -0.03 & 0.97 & .564 & -0.26 & 0.77 & .002 & -0.14 & 0.87 & .154 \\
\hline $\begin{array}{l}\text { HM x IS x } \\
\text { Porn }\end{array}$ & -0.08 & 0.93 & .156 & 0.08 & 1.09 & .247 & 0.06 & 1.06 & .361 \\
\hline Dispersion & 2.70 & & & 3.01 & & & 2.72 & & \\
\hline
\end{tabular}
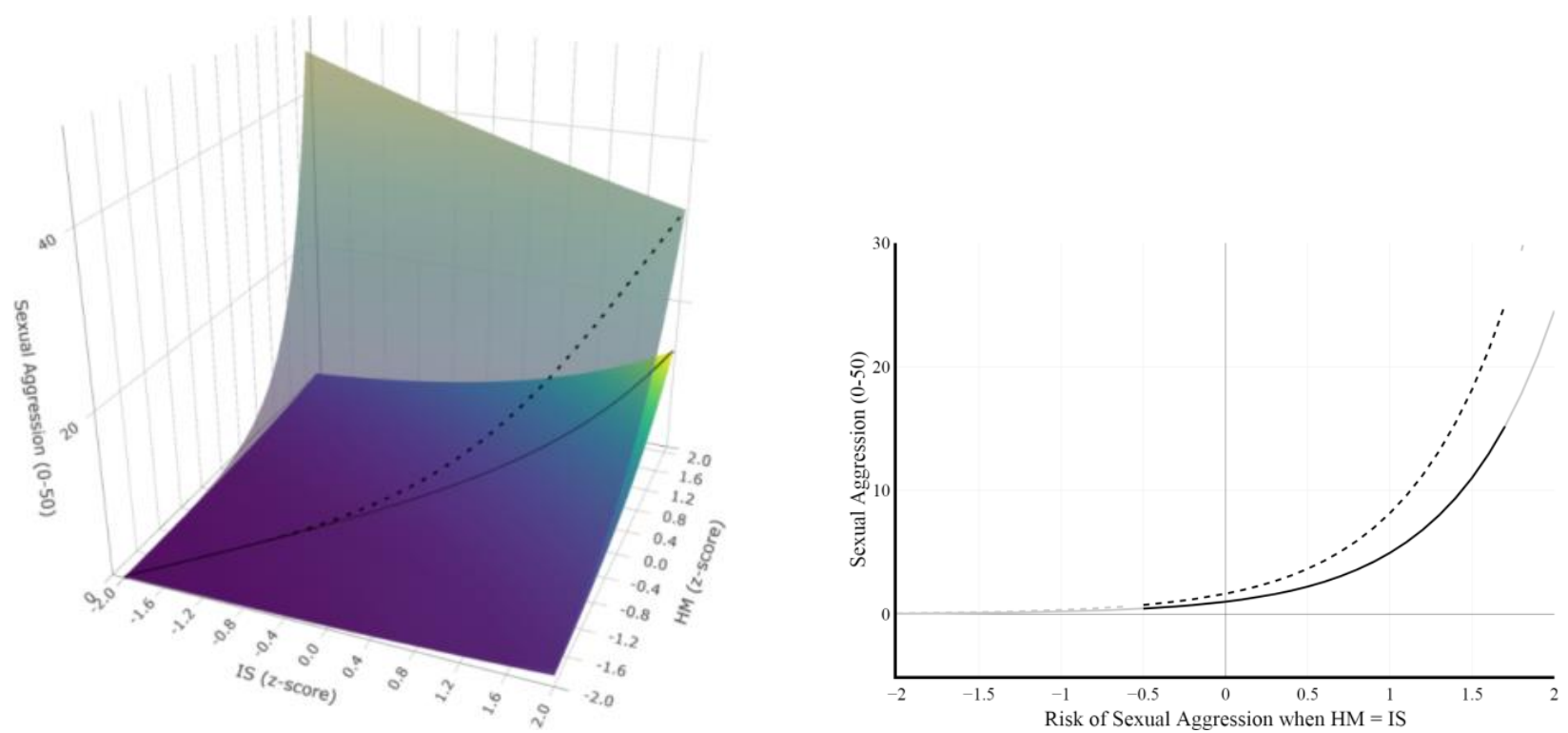

Figure 3a. Study 1: Mechanical Turk sample $(N=1,528)$ 

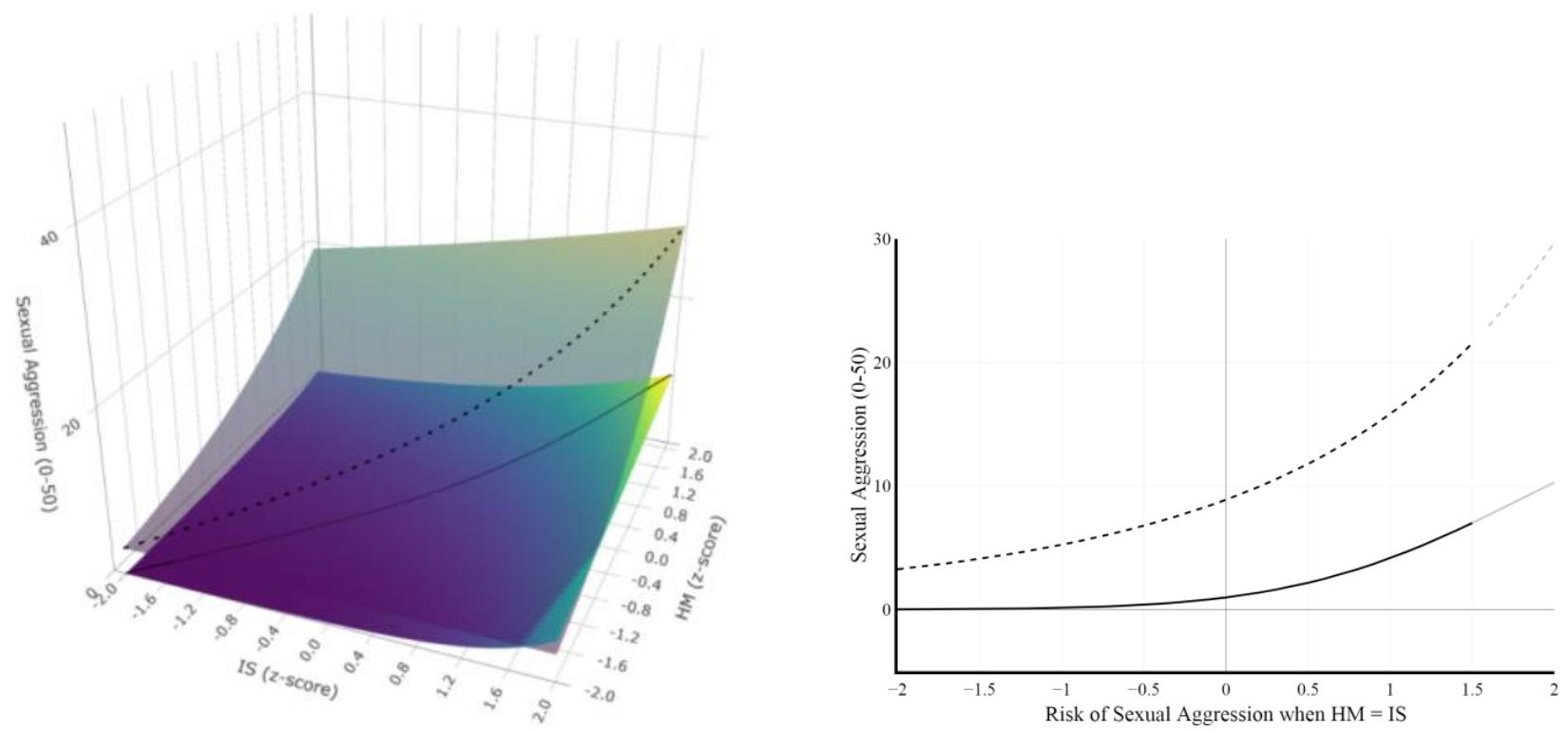

Figure 3b. Study 2: Canadian student sample $(N=1,049)$
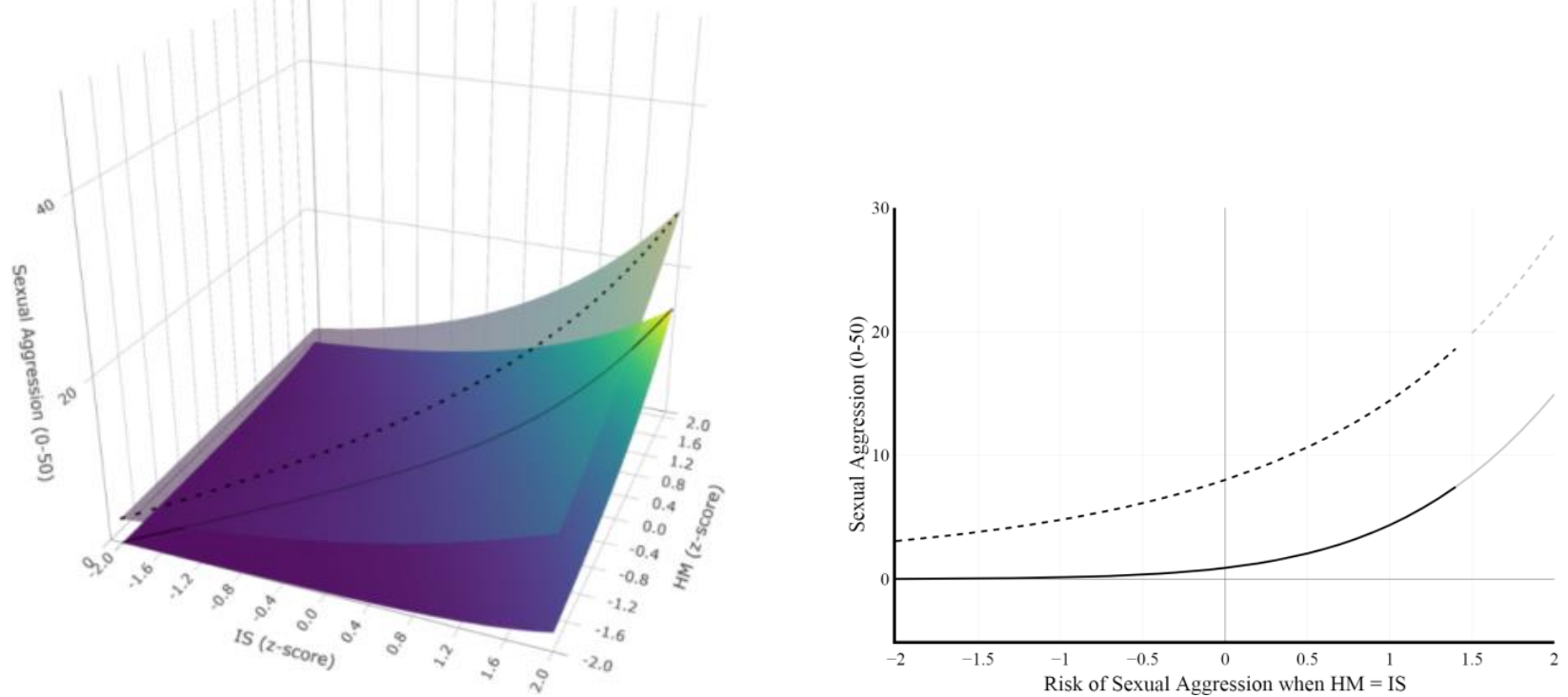

Figure 3c. Study 3: Canadian non-student sample $(N=905)$

Figure 3. Figures 3a-c plot the negative binomial regression results for PMU from Studies 1-3. Opaque surfaces and solid lines depict predictions for "never" using pornography while transparent surfaces and hashed lines depict predictions for using pornography "very frequently." The left-hand panels provide an overview of the prediction space while the right-hand panels focus on the simple main effects of PMU when HM = IS (gray lines indicate regions of nonsignificance). Despite negative interactions involving PMU, substantial positive main effects suggest that linear differences in sexual aggression between frequent pornographic magazine users and non-users increased as HM and IS both increased. 
In Study 1 (Mechanical Turk), there was a significant positive interaction between HM and pornographic magazine use, $b=0.19, p=.001$, IRR $=1.20$, which indicated that the nonlinear association between PMU and sexual aggression was stronger among men who were high in HM (see Figure 3a). In Study 2, a significant negative interaction between pornographic magazine use and IS, $b=-0.26, p=.002, \mathrm{IRR}=0.77$, reduced the non-linear association between PMU and sexual aggression when IS was high (see Figure 3b). Conversely, in Study 3, a significant negative interaction with $\mathrm{HM}, b=-0.20, p=.002, \mathrm{IRR}=0.82$, reduced the association between PMU and sexual aggression among men who were high in HM (See Figure $3 c)$.

Because of these qualifying interactions, tests of simple main effects for use of PMU when HM = IS tended to indicated that use of pornographic magazines was generally positively associated with sexual aggression among men, and that the size of the linear difference in sexual aggression between non-users and high frequency users of pornographic magazines increased as HM and IS both increased together (see Figure 3a-c, right side-panels). Only in Study 1 was pornographic magazine use was not associated with sexual aggression among men who were low in HM and IS (see Figure 3a, right side-panel). It is also interesting to note that across all three studies, non-linear simple main effects of PMU were not significant among participants who were highest in HM and IS. We believe that this was caused by a combination of negative interaction effects involving PMU as well as compounding increases in the magnitude of standard error at extreme scores of HM and IS in these models.

Inconsistent support for the Confluence Model was found when CPU was analyzed with negative binomial regressions. In this case, LRTs indicated that adding components involving CPU to the base model involving HM and IS significantly improved fit in Study $1, \chi^{2}(4)=15.91$, 
$p=.003$, and Study 3, $\chi^{2}(4)=15.91, p=.003$, but not Study $2, \chi^{2}(4)=8.71, p=.069$. An examination of regression parameters (see Table 6) indicated significant negative interactions between CPU and HM in the Study 1 (Mechanical Turk), $b=-0.17, p=.001, I R R=0.85$, and Study 3 (Canadian non-student), $b=-0.16, p=.020, I R R=0.85$ and a further positive main effect for CPU within Study 3 (Canadian non-student sample), $b=0.23, p=.001$, IRR $=1.26$.

No further predictors involving CPU were found (see Table $7 \&$ Figure 4).

Table 7

Results of Negative Binomial Regression Approach Predicting Sexual Aggression with CPU

\begin{tabular}{|l|c|c|c|c|c|c|c|c|c|}
\hline & \multicolumn{3}{|c}{$\begin{array}{c}\text { Sample 1 } \\
\text { (Mechanical Turk) }\end{array}$} & \multicolumn{3}{c|}{$\begin{array}{c}\text { Study 2 } \\
\text { (Canadian Students) }\end{array}$} & \multicolumn{3}{c|}{ Study 3 } \\
(Canadian Non-Students)
\end{tabular}

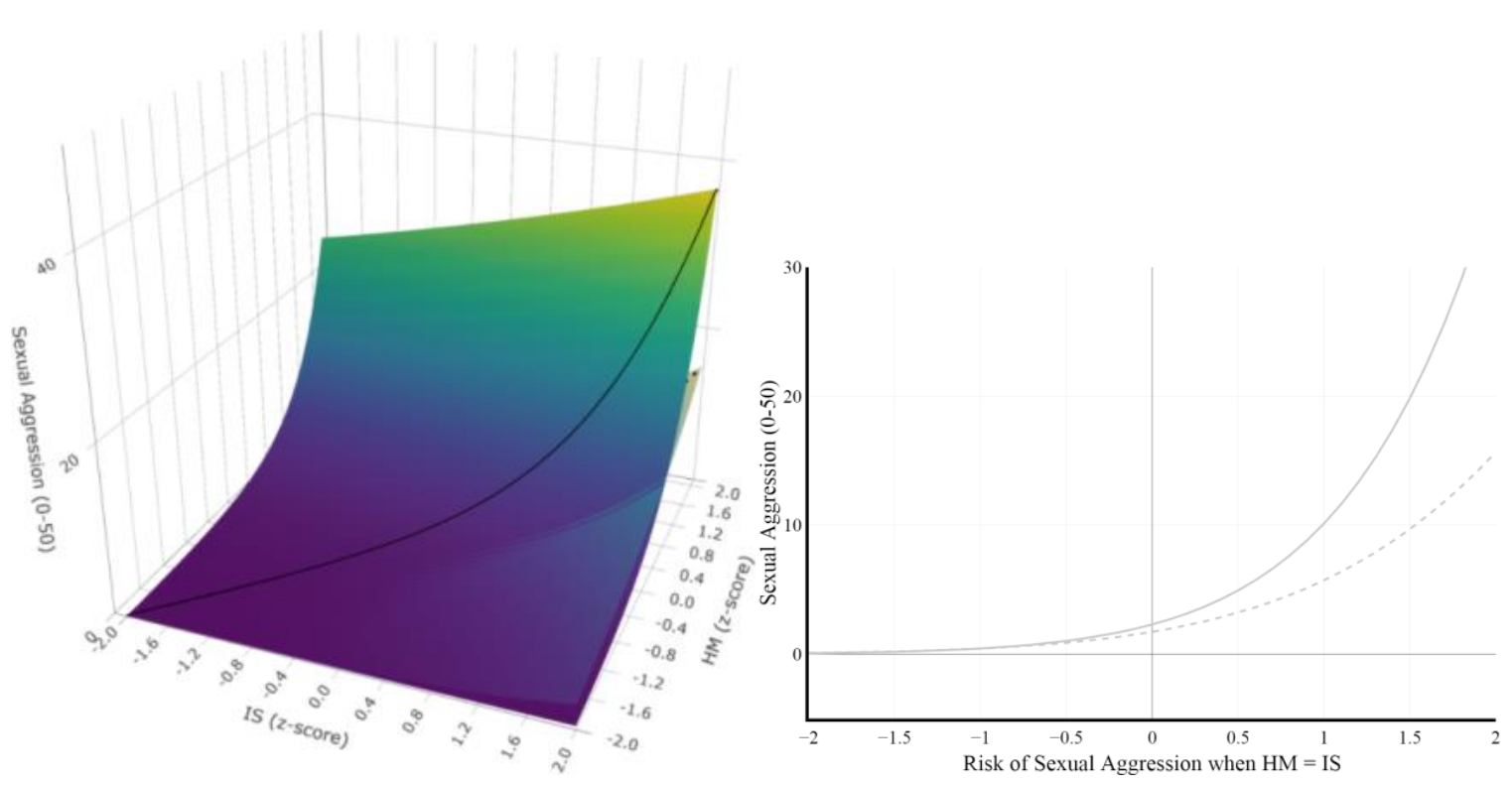


Figure 4a. Study 1: Mechanical Turk sample $(N=1,528)$

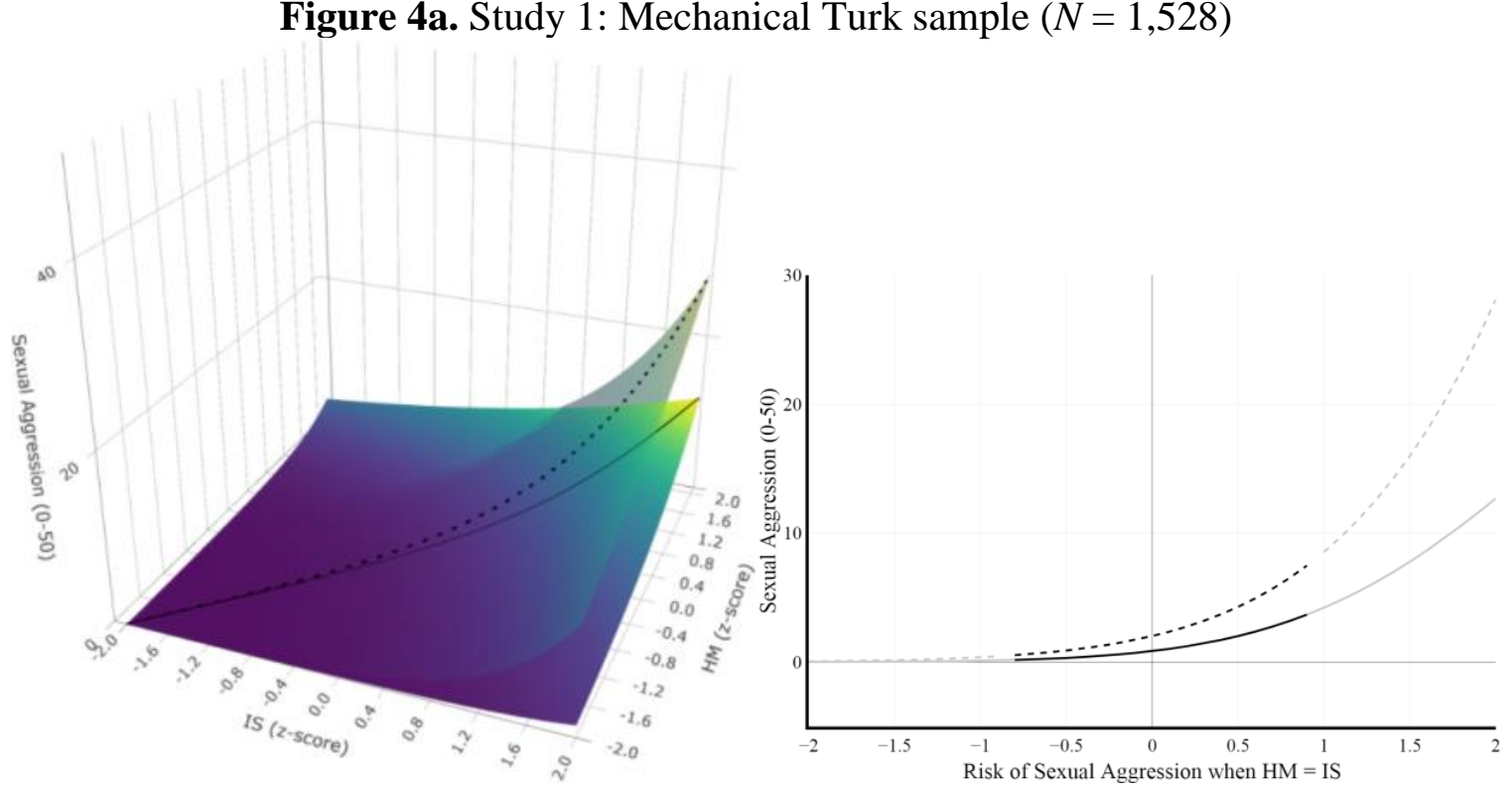

Figure 4b. Study 3: Canadian non-student sample $(N=905)$

Figure 4. Figures $4 \mathrm{a}$ and $4 \mathrm{~b}$ plot the negative binomial regression results for CPU from Studies 1 and 3. Opaque surfaces and solid lines depict predictions for "never" using pornography while transparent surfaces and hashed lines depict predictions for using pornography "more than once a day." The left-hand panels provide an overview of the prediction space while the right-hand panels focus on the simple main effects of CPU when HM = IS (gray lines indicate regions of non-significance). Partial support for Confluence Model theorizing can be found in Study 3 but not Study 1 where using pornography was found to reduce reports of sexual aggression among men who were high in HM.

Tests of simple main effects when HM = IS indicated that CPU was not associated with sexual aggression along this line in Study 1 (see Figure 4a). In contrast, in Study 3, CPU was found to have a positive non-linear association with sexual aggression among men with average scores in HM and IS.

\section{Discussion}

The Confluence Model (Malamuth et al., 2000) assertion that pornography use increases the risk of sexual aggression among men who are high but not low in the predisposing risk factors of HM and IS was tested in three large cross-sectional samples. Results with respect to this hypothesis were found to vary as a function of both how the analyses were conducted and 
how pornography use was measured. When data were analyzed with an anachronistic metric of pornography use, one that was limited to the use of specific pornographic magazines among a minority of our research participants, the results were consistent with Confluence model predictions concerning pornography use. However, analyses involving a more inclusive contemporary measure of pornography use which assessed the consumption of text, pictures, and videos, both online and offline, generally did not support Confluence Model predictions concerning pornography use.

Although the pattern of results was not perfectly consistent across studies, we are inclined to interpret the results concerning pornographic magazine use, on their own, as supportive of Confluence Model predictions. Regardless of how the data were analyzed, the use of pornographic magazines was correlated with self-reported sexual aggression, and stronger linear associations were evident among men with higher predisposed risk of sexual aggression, especially with respect to HM. The total variance in self-reported sexual aggression accounted for by pornographic magazine use was moderate (9-17\% in multiple regression analysis; IRRs ranged from $1.31-1.86$ ) and with respect to the multiple regression results, considerably larger than the reported estimate from a recent meta-analysis concerning "sexualized media" (Burnay et al., 2021). It possible that the analytical inclusion of potential confounding variables, such as sex drive (see Baer et al., 2015) would have reduced the magnitude of these effects. However, considering the amount of variance explained by pornographic magazine use, we doubt that the association between this measure and sexual aggression could be attributed to the "crud factor" if relevant confounding variables were considered (see Ferguson \& Hartley, 2020; Meehl, 1990).

In contrast to the findings regarding pornographic magazine use, the contemporary measure of pornography use was generally not related to sexual aggression, either on its own, or 
in confluence with other risk factors for sexual aggression. At a bivariate level, this measure of pornography use was unrelated to sexual aggression in two samples and weakly related to sexual aggression $(r=.07)$ in only one. Similarly, in the context of Confluence Model risk factors of HM and IS, across three samples, and six analytic tests, only one analysis was somewhat consistent with Confluence Model expectations. Among Canadian non-students, a negative binomial regression model indicated that pornography use had a non-linear relationship with sexual aggression, which, when combined with high levels of IS, which also had a non-linear association with sexual aggression, resulted in Confluence-like synergy when both pornography use and IS were moderately high. Importantly, this model also indicated a negative interaction between pornography use and HM. This interaction inhibited not only the specific synergy between pornography use and HM, but also the synergy between pornography use, HM, and IS which a strict interpretation of the Confluence Model stipulates, and furthermore suggested that pornography use may suppress sexual aggression among men who were high in HM and low in IS. If we attribute the differences between Canadian students and non-students to the vagaries of sampling variation, the net non-linear association between the contemporary measure of pornography use and sexual aggression disappears when the results are pooled meta-analytically across the three studies, $b=-0.004, S E=0.038, W=0.012, p=.914$. Consequently, we are inclined to interpret the evidence regarding the contemporary measure of pornography use across these three studies as inconsistent with Confluence Model predictions about pornography use.

It was not intuitively apparent to us why the results for pornographic magazine use should differ so sharply from those of our more contemporary measure of pornography use. In fact, at first we believed that the findings for pornographic magazine use in Study 1 might just have been a sampling aberration (i.e. Type 1 error). Pornographic magazines use has declined 
very substantially since the advent of the Internet and we did not expect many of our participants to report use of such materials. As best as we can tell, circulation rates for flagship magazines like Playboy, Penthouse, and Hustler, have dropped from around 5 million issues each to around 100,000-200,000 issues each (Hunter, 2018; Quarnstrom, 2015; Watson, 2021; Wikipedia, 2021c), and magazines like Oui, Chic, and Genesis appear to have ceased publication (Wikipedia, 2021b, 2021a). Indeed, 72\% of the participants in Study 1 reported "Never" using a pornographic magazine compared to $19 \%$ of the participants in Malamuth et al. (2000). However, confirmation of these results across two further large sample studies suggests to us that something notable is occurring here.

One possibility, raised by several colleagues, is that socio-historical changes account for this discrepancy in results. After all, the data analyzed by Malamuth et al., (2000) were collected in the 1980s and much has changed in the intervening decades, particularly with respect to pornography use, its content, and how it is accessed. If all we had found was that our contemporary measure of pornography use did not replicate the pattern outlined by Confluence Model theory, then changes in societal norms regarding pornography use and sexual aggression, or differences in education or gender socialization as they pertain to these issues, would seem like an entirely reasonable explanation for the null effects we report here (for a similar argument about non-replication in pornography research, see Balzarini et al., 2017). However, we also found that when we followed Malamuth's et al.'s (2000) methodology for measuring pornography use by focusing on the use of pornographic magazines, we essentially replicated their Confluence Model findings. To us, this replication suggests a high degree of stability in the interrelationships between pornographic magazine use and sexual aggression, despite the sociohistorical changes that may have taken place. For socio-historical changes to account for the 
current pattern of inconsistent findings between the two different measures of pornography use, we would have to assume that our replication of Confluence Model interactions with pornographic magazine use represents a different psycho-behavioral process than was uncovered by the interaction reported by Malamuth et al., (2000). While admittedly possible, we are not convinced that this is the case.

It has also been suggested to us that the discrepancy between findings with different measures of pornography use is possibly driven by differences in age. According to this line of thinking, older individuals, who came of age before Internet pornography was widely available, may retain a penchant for pornographic magazine use and also report higher rates of sexual assault because they have had more opportunity to engage in such behaviors. While on the surface it may seem like a plausible supposition, it cannot explain the current findings; recruitment in all three samples was limited to young adult males between 18 and 24 years of age. Nevertheless, for the sake of diligence, we tested this suggestion statistically and found that it has no merit in the current samples. Controlling for age, and interactions between age, HM, and IS, did not change the results appreciably in any of three studies.

We are, however, in general agreement that there may be something unique about the minority of men who report at least some pornographic magazine use that is not a hallmark of more general pornography users. As outlined by Kohut et al. (2020), the use of pornographic magazines involves specific — and in the current age, quite atypical—pornography acquisition behaviors. Although pornographic magazines can be obtained through the mail using subscription services, the alternative involves visiting a physical location, selecting from a limited number of available options that have been stocked by the retailer, and making a public purchase at some cost that communicates to any and all witnesses the sexual interests and intent 
of the purchaser. Compared to the private and freely available pornography of nearly any genre on the Internet, acquiring magazines in physical stores is more effortful and potentially much more self-disclosing ${ }^{3}$. It is also possible that the act of purchasing can be used as a form of illconsidered flirtation with, or even the intentional sexual harassment of, female store employees. In such instances the purchase of a pornographic magazine may serve as a "cover" for potentially unwanted behavior (e.g., "Look what a stud I am" or " "Let's see how she'll react"). Given the anecdotal nature of this account, which was provided to us by a former member of our lab who had experienced unwanted solicitations of this kind, we are unsure how often such events generally occur in the sale of pornographic magazines. Nevertheless, the fact that such events can occur suggests again to us that men with certain personality profiles might be more attracted to the purchase of pornographic magazines in brick-and-mortar stores because of the perceived interpersonal "opportunities" that such purchases provide.

Importantly, while the purchase of pornographic magazines may be unusual in this day and age because of plentiful, effortless, low-cost, and private alternatives, the public nature of magazine purchase, as well as the opportunities to commit acts of sexual harassment during such purchases have not fundamentally changed since 1984. If the social context of the acquisition of pornographic magazines has not changed appreciably, this may explain comparability of results between the current findings and past Confluence model research involving magazine use (see Malamuth et al., 2000, 2012; Vega \& Malamuth, 2007) despite other socio-historical changes. Whether or not the social context of this acquisition behavior has changed, we strongly suspect

\footnotetext{
${ }^{3}$ In fact, upon recognizing the robustness of the findings for pornographic magazines, it took the first author several hours of driving around a mid-sized Canadian city to even find an outlet that still sold pornographic magazines. And once he did, he was immediately confronted by an internal dialogue of self-presentation concerns: "Have people noticed that I am scanning the top shelf of the magazine display?"; "What would the cashier think of me if I bought that issue of 18teen? Perhaps I should get Over Thirty instead?"; "I've been staring at these magazines too long"; etc.
} 
that individuals who engage in this behavior today represent a distinct individual-difference profile among young adult male pornography users. We speculate that such men should be more impulsive, lower in social desirability concerns, and higher in Dark Triad traits like psychopathy and narcissism than other pornography users and non-users.

Alternatively, it may also be the case that consistent associations between the use of pornographic magazines and self-reported sexual aggression are the product of intentional survey sabotage. Deliberate lying in survey responses has long been documented (Cimpian \& Timmer, 2020; Fan et al., 2002), and some researchers attribute such behavior to intentional efforts to appear humorous, or to shock or upset (i.e., to "troll”) survey administrators (Lopez \& Hillygus, 2018). In such cases, a small subset of survey participants simultaneously claim to identify with low frequency identities, hold unlikely opinions, and frequently engage in atypical behaviors, and controlling for such respondents can dramatically influence a study's results (Cimpian \& Timmer, 2020; Fan et al., 2002; Lopez \& Hillygus, 2018; Robinson-Cimpian, 2014). On the basis of such research, and the very low circulation rates of pornographic magazines, we suspect that questions concerning the use of pornographic magazines, and to even greater extent, the commission of sexual aggression, may be attractive targets for exaggeration among malicious survey respondents. Very few of our respondents reported "somewhat frequent" or "very frequent" use of pornographic magazines (4-5\%, depending on the study), and similarly few reported obtaining non-consensual sexual intercourse with women through the use physical force (5-7\%, depending on the study). In contrast, pornography use that is not restricted to magazine use appears to be quite normative for young adult males, so we would not expect responses to our more inclusive measure of pornography use to be similarly influenced by mischievous participants. 
It is important to note that while we believe that participant sabotage may be viable explanation for why self-reported pornographic magazine use may be related to self-reported sexual aggression in the current age, we do not believe that it would apply to the results reported by Malamuth et al. (2000). In 1984, pornographic magazine use was more normative, and the average frequency of use was too high in their sample to be impacted substantially by a small number of problematic participants. If the current pattern of results regarding pornographic magazine use are caused by survey trolling, and the similarity to past Confluence Model findings is simply coincidental, then it would lend credit to the suggestion that socio-historical changes have diminished previously existing connections between pornography use and sexual aggression. In any case, further work in this area should carefully consider methods to detect, and potentially control for, the undue influence of such respondents.

Although the current findings partially support Confluence Model predictions regarding pornography use and sexual aggression, at least with respect to pornographic magazine use, the discrepancy between the results of the two measures of pornography use is difficult to explain with Confluence Model theory. According to Confluence Model theory, exposure to pornography creates or reinforces cognitions, emotions, and attitudes that contribute to sexual violence among at risk men (Hald \& Malamuth, 2015; Malamuth et al., 2000). While content analyses that directly compare the extent of violence in different sources of pornography are scarce, existing research indicates that violence is actually less common in printed magazines than online materials (Barron \& Kimmel, 2000). If sexually violent material is less common in pornographic magazines, why is it that that use of pornographic magazines, both in the current study and in Malamuth et al., (2000), but not the use of Internet pornography, is correlated with sexual aggression among at risk men? 
Perhaps our findings only seem inconsistent with Confluence Model theorizing because our inferences hinge on the interpretation of two general measures of pornography use rather than more direct measures of violent pornography use. In contrast to our approach, recent investigations of pornography use within the context of the Confluence Model have increasingly focused on the use of violent, coercive, or otherwise "extreme" depictions in pornography (Huntington et al., 2020; Malamuth et al., 2021; Wright et al., 2021). Importantly, research interest in the use of specific problematic content is consistent with speculation on the part of Malamuth and others that Confluence Model "effects" may be more pronounced with respect to such materials (Malamuth, 2018; Malamuth et al., 2000). Therefore, it is possible, and indeed, very likely from our perspective, that our contemporary measure of pornography was not related to sexual aggression because it lacked theoretical meaningful specificity by not assessing use of violent or coercive content. At the same time, we find it puzzling that the measure of pornographic magazine use, which is equally non-specific with respect to exposure to violence and coercion, and probably less likely to indicate actual instances of exposure to sexual violence and coercion, was reliably correlated with self-reported sexual aggression across the three studies that we report. To us, this implies that evidence of correlations between pornographic magazine use and sexual aggression both in the current, and past Confluence Model research, may not actually reflect the "effects" of exposure to problematic content in pornography, but some other mechanism instead.

The idea that specific exposure to sexually violent material may add "fuel to the fire" among men who are at risk of sexual aggression seems reasonable in our view, but this theoretical assumption has not actually been demonstrated empirically within Confluence Model research. While synergistic Confluence Model interactions involving HM, IS, and pornography 
use have been reported in studies involving general measures of pornography use (Baer et al., 2015; Malamuth et al., 2000, 2012; Vega \& Malamuth, 2007), three of which involved measures of pornographic magazine use, to our knowledge, these interactions have not emerged among studies that have measured the use of violent or extreme pornography (see, for example, Huntington et al., 2020; Malamuth et al., 2021; Wright et al., 2021). Instead, the available evidence appears to indicate that use of violent or coercive pornography is associated with increased risk of sexual aggression for all consumers of pornography to a similar degree, regardless of their level of predisposed risk of sexual aggression. Such evidence is at odds with Confluence Model theorizing regarding the synergistic influence of sexual aggression risk factors and is therefore an important unresolved issue that deserves to be prioritized in future research.

Finally, it is important to note that the results of the current studies largely support other aspects of the Confluence Model. In contrast to the results for pornography use, across all three studies and two analytic methods, we found consistent evidence that HM and IS interacted synergistically when predicting self-reported sexual aggression. These predictors, and their interaction, appear to be very reliable correlates of sexual aggression and account for a sizeable portion of variance in this behavior and this in itself is an important finding to emphasize given the generally low rates of replicated results in social science research.

The consistent results concerning the associations among HM, IS, and sexual aggression, suggest that future theory- and research-based interventions to reduce sexual aggression should concentrate on these constructs. Unfortunately, specific recommendations in this regard are complicated somewhat by discrepancies between the conceptual and operational natures of HM and IS. Hostile masculinity, for example, is conceptually defined as a personality profile 
(Malamuth \& Hald, 2017) which suggests some degree of stability and resistance to change. At the same time, HM is generally operationally defined using a combination of attitudinal assessments (e.g., attitudes accepting violence towards women, hostility towards women) and personality inventories (e.g., narcissism, negative masculinity). To the extent that attitudinal components of HM are dissociable from personality aspects, they may prove amenable to change through a range of social psychological approaches such as persuasive communication, evaluative conditioning, and cognitive dissonance (Pedneault et al., 2021). There are also definitional issues with IS. While IS is conceptually defined as having a having low attachment towards sexual partners and a lack of empathy for them (Malamuth \& Hald, 2017), it has been operationally defined in the current study and in several past studies involving pornography use (Baer et al., 2015; Malamuth et al., 2000, 2012) as the age of first intercourse and number of sexual partners. Rather than indicating a lack attachment towards and empathy for their sexual partners, such measures might simply represent more sexual experience, and therefore, more opportunities for sexual aggression. Depending on the actual mechanism through which IS is related to sexual aggression, radically different intervention approaches may be necessary (e.g., inhibiting sexual experience vs. promoting empathy). Consequently, further research should continue to probe the nature of HM and IS and the malleability of these constructs, and seek to develop intervention strategies to determine if reductions in HM and IS can diminish sexual aggression against women.

\section{Limitations}

The current study, as with all preceding cross-sectional Confluence Model research (Baer et al., 2015; Hald \& Malamuth, 2015; Malamuth et al., 2000; Vega \& Malamuth, 2007), cannot, by definition, confirm the model's hypothesized causal influences of HM, IS, and pornography 
use on sexual aggression. Indeed, the tendency to represent correlational findings as evidence of causation is one of our central concerns in this area of research. To us, it appears commonplace in this field for researchers to provide tacit acknowledgment of the limits of correlational data, while continuing interpret such data from a single causal perspective. This practice is duplicitous and should be challenged at every turn (Fisher \& Kohut, 2020).

Issues of pornography use measurement are of more serious concern with respect to the inferences that we have drawn from the current data. There is a general tendency for behavioral scientists to look down on single item measures. Somewhat paradoxically, the field of pornography research is generally quite critical of this methodological issue despite the widespread and continuing use of single item assessments (Kohut, Balzarini, et al., 2020; Marshall \& Miller, 2019; Short et al., 2012). In this particular case, we have independent evidence concerning the validity of the single-item contemporary measure of pornography use that was used in this study. Specifically, we employed this measure of pornography use in a separate study of $N=422$ men and women who were also asked to respond to other single and multi-item assessments of pornography use. In that dataset (available here: https://osf.io/ymfhp/?view_only=be4fac78eefc4e30a726feb002805227), the current measure was highly correlated with single items measures used by Bridges and Morokoff (2011), $r=.87$, Carrol et al. (2008),$r=.90$, and Lambert et al., (2012), $r_{S t u d y 1}=.87, r_{S t u d y 2}=.86$. Our measure of pornography was also highly correlated with multi-item assessments used by Leonhardt \& Willoughby (2019), $r=.74$, and Hald (2006),$r=.83$, although in each case, a single item was erroneously omitted from both of these inventories on our survey. On the basis of such correlations, it would seem that the measure used in the current study is at least as valid as other measures of pornography use that have been published in the literature. 
The bigger measurement issue here, from our perspective, is that neither of the two pornography use measures used in the current study, nor any that we are aware of in the broader literature, have been properly validated against objective observations of actual pornography use. Borrowing from similar lines of research where the accuracy of self-reported behaviors appears quite questionable, Kohut et al. (2020) have pointed out that survey research concerning pornography use may better reflect self-perceptions of such use, or otherwise biased reports of such use, than actual use itself. This is yet one more reason that researchers should guard against the tendency to interpret correlations from a causal perspective.

Lastly with respect to the measurement of pornography use in the current study, one reviewer has taken issue with the definition of pornography that was provided to our participants. Unlike other approaches, the definition used in the current study included the depiction of nudity in the absence of explicit sexual behavior and did not mention the arousal function of pornography. These choices were deliberate because research suggests that depictions of nudity in the absence of sexual behavior are perceived to be more pornographic than non-nude depictions (Kohut, 2014; Willoughby \& Busby, 2016) and cues indicating nudity emerged as an important contributor to the family resemblance structure of this concept in earlier research (Kohut, 2014). In our view, the value of the including the "arousal" function in definitions of pornography that are provided to participants is questionable because arousal judgments are inherently subjective though other researchers and theorists may feel differently on this matter.

It has been brought to our attention the operationalization of HM that was used in this study is not fully consistent with the theoretical definition of this construct. While the measures that we employed in this study are the same as those presented in Malamuth et al., (2000), neither study included a measure of "sexual gratification from controlling or dominating 
women." (Malamuth et al., 2012, p. 429) in their assessment of HM. We do not see this as a major shortcoming because our measure of HM behaved as expected, both on its own, and in interaction with IS and pornographic magazine use, and other Confluence Model studies have found synergistic interactions between HM, IS and pornography use without including an assessment of sexual dominance motives in their measures of HM (see Baer et al., 2015; Malamuth et al., 2012). Although we feel that the importance of this component of HM with respect to interactions with pornography use is debateable, as methodologically-oriented researchers, we generally value operational definitions that cleave tightly to their conceptual definitions. Consequently, we recommend that future research in this domain include sexual dominance motives in their operationalization definitions of HM.

Finally, it should be clear to most readers that recruiting young male participants from North America necessarily limits the generalizability of our findings. Unfortunately, the same is true of most other tests of pornography's role in Confluence Model theory that we are aware of. Concerns also continue to be raised about the quality of data provided by participants sampled from Mechanical Turk (Kennedy et al., 2020). Fortunately, our conclusions do not rest solely on the analysis of Mechanical Turk data alone and the pattern of results is reasonably similar across all three samples.

\section{Conclusions}

Findings from three large cross-sectional surveys support some specific aspects of Confluence Model theorizing but not others. Importantly, the discrepancy in findings are not easily explained with Confluence Model theorizing concerning pornography use and sexual aggression, and suggests to us that important third variables (e.g., impulsiveness, social desirability, "trolling," etc.) remain viable alternative explanations for the observed pattern of 
correlations. Beyond issues related to the Confluence Model specifically, the divergent findings for two operationalizations of pornography use, which were uncorrelated across our studies, should serve as a warning to the field of the non-equivalence of different metrics of pornography use. Such results further underscore the need to adopt common well-validated measures of pornography use across studies to build a cumulative science (Kohut, Balzarini, et al., 2020). 


\section{References}

Abbey, A., Jacques-Tiura, A. J., \& Lebreton, J. M. (2011). Risk factors for sexual aggression in young men: An expansion of the confluence model. Aggressive Behavior, 37(5), 450-464. https://doi.org/10.1002/ab.20399

Baer, J. L., Kohut, T., \& Fisher, W. A. (2015). Is pornography use associated with anti-woman sexual aggression? Re-examining the confluence model with third variable considerations. The Canadian Journal of Human Sexuality, 24(2), 160-173. https://doi.org/10.3138/cjhs.242-A6

Barron, M., \& Kimmel, M. (2000). Sexual violence in three pornographic media: Toward a sociological explanation. Journal of Sex Research, 37(2), 161-168. https://doi.org/10.1080/00224490009552033

Bergkvist, L., \& Rossiter, J. R. (2007). The predictive validity of multiple-item versus singleitem measures of the same constructs. Journal of Marketing Research, 44(2), 175-184. https://doi.org/10.1509/jmkr.44.2.175

Burnay, J., Kepes, S., \& Bushman, B. J. (2021). Effects of violent and nonviolent sexualized media on aggression-related thoughts, feelings, attitudes, and behaviors: A meta-analytic review. Aggressive Behavior, June. https://doi.org/10.1002/ab.21998

Check, J. V. P. (1984). The Hostility toward Women Scale. (Doctoral Dissertation). https://mspace.lib.umanitoba.ca/handle/1993/23279

Cimpian, J. R., \& Timmer, J. D. (2020). Mischievous responders and sexual minority youth survey data: A brief history, recent methodological advances, and implications for research and practice. Archives of Sexual Behavior, 49(4), 1097-1102. https://doi.org/10.1007/s10508-020-01661-7 
Diamantopoulos, A., Sarstedt, M., Fuchs, C., Wilczynski, P., \& Kaiser, S. (2012). Guidelines for choosing between multi-item and single-item scales for construct measurement: A predictive validity perspective. Journal of the Academy of Marketing Science, 40(3), 434449. https://doi.org/10.1007/s11747-011-0300-3

Ellis, D. A., Davidson, B. I., Shaw, H., \& Geyer, K. (2018). Do smart phone usage scales predict use? International Journal of Human-Computer Studies, 130, 86-92. https://doi.org/10.31234/osf.io/6fjr7

Fan, X., Miller, B. C., Christensen, M., Park, K. E., Grotevant, H. D., van Dulmen, M., Dunbar, N., \& Bayley, B. (2002). Questionnaire and interview inconsistencies exaggerated differences between adopted and non-adopted adolescents in a national sample. Adoption Quarterly, 6(2), 7-27. https://doi.org/10.1300/J145v06n02_02

Ferguson, C. J., \& Hartley, R. D. (2020). Pornography and sexual aggression: Can meta-analysis find a link? Trauma, Violence, and Abuse. https://doi.org/10.1177/1524838020942754

Fisher, W. A., \& Barak, A. (2001). Internet pornography: A social psychological perspective on internet sexuality. Journal of Sex Research, 38(4), 312-323. https://doi.org/10.1080/00224490109552102

Fisher, W. A., \& Kohut, T. (2020). Reading Pornography: Methodological Considerations in Evaluating Pornography Research. Journal of Sexual Medicine, 17(2). https://doi.org/10.1016/j.jsxm.2019.11.257

Fisher, W. A., Kohut, T., di Gioacchino, L. A., \& Fedoroff, P. (2013). Pornography, sex crime, and paraphilia. Current Psychiatry Reports, 15(6), 362-369. https://doi.org/10.1007/s11920-013-0362-7 
Hald, G. M., \& Malamuth, N. M. (2015). Experimental effects of exposure to pornography: The moderating effect of personality and mediating effect of aexual arousal. Archives of Sexual Behavior, 44(1), 99-109. https://doi.org/10.1007/s10508-014-0291-5

Hauser, D. J., \& Schwarz, N. (2016). Attentive Turkers: MTurk participants perform better on online attention checks than do subject pool participants. Behavior Research Methods, 48(1), 400-407. https://doi.org/10.3758/s13428-015-0578-z

Hunter, B. (2018, June 11). HOT OFF THE PRESSES: Bankrupt Penthouse magazine sells for just \$11M. Toronto Sun. https://torontosun.com/news/world/bankrupt-penthouse-magazinesells-for-just-11m

Huntington, C., Pearlman, D. N., \& Orchowski, L. (2020). The confluence model of sexual aggression: An application With adolescent males. Journal of Interpersonal Violence. https://doi.org/10.1177/0886260520915550

Kennedy, R., Clifford, S., Burleigh, T., Waggoner, P. D., Jewell, R., \& Winter, N. J. G. (2020). The shape of and solutions to the MTurk quality crisis. Political Science Research and Methods, 8(4), 614-629. https://doi.org/10.1017/psrm.2020.6

Kohut, T., Balzarini, R. N., Fisher, W. . A., Grubbs, J. B., Campbell, L., \& Prause, N. (2020). Surveying pornography use: A shaky science resting on poor measurement foundations. Journal of Sex Research, 57(6), 722-742. https://doi.org/10.1080/00224499.2019.1695244

Kohut, T., Balzarini, R. N., Fisher, W. A., \& Campbell, L. (2018). Pornography's associations with open sexual communication and relationship closeness vary as a function of dyadic patterns of pornography use within heterosexual relationships. Journal of Social and Personal Relationships, 35(4), 655-676. https://doi.org/10.1177/0265407517743096 
Kohut, T., Fisher, W. A., \& Campbell, L. (2017). Perceived effects of pornography on the couple relationship: Initial findings of open-ended, participant-informed, "bottom-up” research. Archives of Sexual Behavior, 46(2), 585-602. https://doi.org/10.1007/s10508-016-0783-6

Kohut, T., Landripet, I., \& Štulhofer, A. (2020). Testing the Confluence Model of the Association Between Pornography Use and Male Sexual Aggression: A Longitudinal Assessment in Two Independent Adolescent Samples from Croatia. Archives of Sexual Behavior. https://doi.org/10.1007/s10508-020-01824-6

Koss, M. P., Gidycz, C. A., \& Wisniewski, N. (1987). The scope of rape: Incidence and prevalence of sexual aggression and victimization in a national sample of higher education students. Journal of Consulting and Clinical Psychology, 55(2), 162-170. https://doi.org/10.1037/0022-006X.55.2.162

Koss, M. P., \& Oros, C. J. (1982). Sexual experiences survey: A research instrument investigating sexual aggression and victimization in a national sample of higher education students. Journal of Consulting and Clinical Psychology, 50(3), 455-457. https://doi.org/10.1037/0022-006X.50.3.455

Lakens, D. (2014). Performing high-powered studies efficiently with sequential analyses. European Journal of Social Psychology, 44, 701-710. https://doi.org/10.1002/ejsp.2023

Lopez, J., \& Hillygus, D. S. (2018). Why so serious?: Survey trolls and misinformation. In SSRN Electronic Journal. https://doi.org/10.2139/ssrn.3131087

Malamuth, N. M. (1986). Predictors of naturalistic sexual aggression. Journal of Personality and Social Psychology, 50(5), 953-962. https://doi.org/10.1037/0022-3514.50.5.953

Malamuth, N. M. (2017, February 6). Personal Correspondence. 
Malamuth, N. M. (2018). "Adding fuel to the fire"? Does exposure to non-consenting adult or to child pornography increase risk of sexual aggression? Aggression and Violent Behavior, 41, 74-89. https://doi.org/10.1016/j.avb.2018.02.013

Malamuth, N. M., Addison, T., \& Koss, M. P. (2000). Pornography and sexual aggression: Are there reliable effects and can we understand them? Annual Review of Sex Research, 11, 2691. https://doi.org/10.1080/10532528.2000.10559784

Malamuth, N. M., \& Hald, G. M. (2017). The confluence mediational model of sexual aggression. In D. P. Boer, A. R. Beech, \& T. Ward (Eds.), The Wiley handbook on the theories, assessment and treatment of sexual offending (Vol. 1, pp. 53-70). John Wiley \& Sons, Ltd. http://www.tandfonline.com/doi/abs/10.1300/J076v23n03_03

Malamuth, N. M., Hald, G. M., \& Koss, M. P. (2012). Pornography, individual differences in risk and men's acceptance of violence against women in a representative sample. Sex Roles, 66(7-8), 427-439. https://doi.org/10.1007/s11199-011-0082-6

Malamuth, N. M., Lamade, R. v., Koss, M. P., Lopez, E., Seaman, C., \& Prentky, R. (2021). Factors predictive of sexual violence: Testing the four pillars of the confluence model in a large diverse sample of college men. Aggressive Behavior, 47(4), 405-420. https://doi.org/10.1002/ab.21960

Malamuth, N. M., Linz, D., \& Heavey, C. L. (1995). Using the confluence model of sexual aggression to predict men's conflict with women: A 10-year follow-up study. Journal of Personality and Social Psychology, 69(2), 353-369. https://doi.org/10.1037/00223514.69.2.353

Malamuth, N. M., Sockloskie, R. J., Koss, M. P., \& Tanaka, J. S. (1991). Characteristics of aggressors against women: Testing a model using a national sample of college students. 
Journal of Consulting and Clinical Psychology, 59(5), 670-681.

https://doi.org/10.1037/0022-006X.59.5.670

Marshall, E. A., \& Miller, H. A. (2019). Consistently inconsistent: A systematic review of the measurement of pornography use. Aggression and Violent Behavior, 48, 169-179. https://doi.org/10.1016/j.avb.2019.08.019

Meehl, P. E. (1990). Why summaries of research on psychological theories are often uninterpretable. Psychological Reports, 66(1), 195-244. https://doi.org/10.2466/pr0.1990.66.1.195

Parkhill, M. R., \& Abbey, A. (2008). Does alcohol contribute to the Confluence Model of sexual assault perpetration? Journal of Social and Clinical Psychology, 27(6), 529-554. https://doi.org/10.1521/jscp.2008.27.6.529

Quarnstrom, L. (2015, May 15). Former editor of Hustler: the Internet was invented to help us get off in peace. Quartz. https://qz.com/394275/former-editor-of-hustler-the-internet-wasinvented-to-help-us-get-off-in-peace/

Robinson-Cimpian, J. P. (2014). Inaccurate estimation of disparities due to mischievous responders: Several suggestions to assess conclusions. Educational Researcher, 43(4), 171185. https://doi.org/10.3102/0013189X14534297

Seto, M. C., Maric, A., \& Barbaree, H. E. (2001). The role of pornography in the etiology of sexual aggression. Aggression and Violent Behavior, 6(1), 35-53. https://doi.org/10.1016/S1359-1789(99)00007-5

Short, M. B., Black, L., Smith, A. H., Wetterneck, C. T., \& Wells, D. E. (2012). A review of internet pornography use research: Methodology and content from the past 10 years. 
Cyberpsychology, Behavior, and Social Networking, 15(1), 13-23.

https://doi.org/10.1089/cyber.2010.0477

Sievert, C. (2020). Interactive web-based data visualization with $R$, plotly, and shiny. Chapman and Hall/CRC. https://plotly-r.com

Swartout, K. M. (2013). The company they keep: How peer networks influence male sexual aggression. Psychology of Violence, 3(2), 157-171. https://doi.org/10.1037/a0029997

Swartout, K. M., Thompson, M. P., Koss, M. P., \& Su, N. (2015). What is the best way to analyze less frequent forms of violence? The case of sexual aggression. Psychology of Violence, 5(3), 305-313. https://doi.org/10.1037/a0038316

van Buuren, S., \& Groothuis-Oudshoorn, K. (2011). MICE: Multivariate imputation by chained equations in R. Journal Of Statistical Software, 45(3), 1-67.

https://doi.org/10.18637/jss.v045.i03

Vega, V., \& Malamuth, N. M. (2007). Predicting sexual aggression: The role of pornography in the context of general and specific risk factors. Aggressive Behaviour, 33, 104-117. https://doi.org/10.1002/ab.20172

Watson, A. (2021, June 1). Playboy's circulation worldwide from 1960 to 2018. Statistica. https://www.statista.com/statistics/485332/playboy-circulation-worldwide/

Wikipedia. (2021a). Chic (pornographic magazine). Wikipedia. https://en.wikipedia.org/wiki/Chic_(pornographic_magazine)

Wikipedia. (2021b). Oui (magazine). Wikipedia. https://en.wikipedia.org/wiki/Oui_(magazine) Wikipedia. (2021c). Penthouse (magazine). Wikipedia. https://en.wikipedia.org/wiki/Penthouse_(magazine) 
Wright, P. J., Paul, B., \& Herbenick, D. (2021). Pornography, impersonal sex, and sexual aggression: A test of the confluence model in a national probability sample of men in the U.S. Aggressive Behavior, 1-10. https://doi.org/10.1002/ab.21978 